\title{
The Effects of the Metal Ion Substitution into the Active Site of Metalloenzymes: A Theoretical Insight on Some Selected Cases
}

\author{
Mario Prejanò, Marta Erminia Alberto, Nino Russo ${ }^{\mathbb{D}}$, Marirosa Toscano * and Tiziana Marino * $\mathbb{D}$ \\ Department of Chemistry and Chemical Technologies, University of Calabria, 87036 Arcavacata di Rende, \\ Cosenza, Italy; mario.prejano@unical.it (M.P.); marta.alberto@unical.it (M.E.A.); nrusso@unical.it (N.R.) \\ * Correspondence: marirosa.toscano@unical.it (M.T.); tiziana.marino65@unical.it (T.M.)
}

Received: 31 July 2020; Accepted: 8 September 2020; Published: 10 September 2020

\begin{abstract}
A large number of enzymes need a metal ion to express their catalytic activity. Among the different roles that metal ions can play in the catalytic event, the most common are their ability to orient the substrate correctly for the reaction, to exchange electrons in redox reactions, to stabilize negative charges. In many reactions catalyzed by metal ions, they behave like the proton, essentially as Lewis acids but are often more effective than the proton because they can be present at high concentrations at neutral $\mathrm{pH}$. In an attempt to adapt to drastic environmental conditions, enzymes can take advantage of the presence of many metal species in addition to those defined as native and still be active. In fact, today we know enzymes that contain essential bulk, trace, and ultra-trace elements. In this work, we report theoretical results obtained for three different enzymes each of which contains different metal ions, trying to highlight any differences in their working mechanism as a function of the replacement of the metal center at the active site.
\end{abstract}

Keywords: metal ions; metalloenzymes; rate determining step; QM cluster; reaction mechanisms

\section{Introduction}

Enzymes are highly performant catalysts in biology and regardless of their location represent "a cog in a larger piece of biochemical machinery" [1]. In fact, the chemical reactions under physiological conditions occur under strict control and can only take place under enzymatic catalysis. Therefore, understanding enzymatic working mechanism is of extreme interest in biology. Moreover, learning about how enzymes work is helpful because this can inspire artificial catalysts for a variety of biotechnological applications ranging from chemical synthesis to the generation of novel biofuels but also for drug design [2].

In some cases, twenty amino acids are not enough to perform the breadth of chemistry handled by enzymes that must resort to additional chemical species to carry out the catalysis. In these cases, non-amino acid components may be either associated or bonded to proteins for improving the kinetic behavior. Metal ions as metal cofactors, present in one-third of all enzymes, help to catalyze biochemical reactions and perform specific physiological functions [3].

Some metal ions are found deeply buried within proteins taking an active part in structural function. A canonical example can be zinc finger proteins where the $\mathrm{Zn}^{2+}$ ions are helpful in adopting the proper shape of the protein allowing it to interact with DNA [4,5]. When the metal ions play a functional role, they can be found at the active site of metalloenzymes and are implicated in a wide range of processes, such as electron transfer, substrate recognition/binding, and catalysis $[6,7]$. Proteins can also incorporate inorganic or organic ligands in their structures, along with metal ions. These groups are largely used in electron-transfer proteins as their redox potentials can conveniently 
be tuned over large ranges. For instance, the methanol dehydrogenase's active site, an enzyme dealt in the present review, contains the pyrroloquinoline quinone (PQQ) cofactor responsible for the redox nature for the enzyme beside the metal ion [8-10].

The role performed by metal ions in the catalytic mechanisms of the metalloenzymes examined in this contribution, although belonging to three different enzymatic classes, i.e., oxidoreductase (methanol dehydrogenase), lyase (nitrile hydratase), and hydrolase (Arginase) are by far the most widespread between enzymes ( $70 \%$ ) (see Figure 1$)$. In fact, they have common general functions, such as the activation of reacting species and the electrostatic stabilization of intermediates and transition states. This is because a specific mechanism may depend on the chemical nature of both the coordinated species and the catalytic site, while the metal ion property invariably exploited is Lewis acidity.

A)

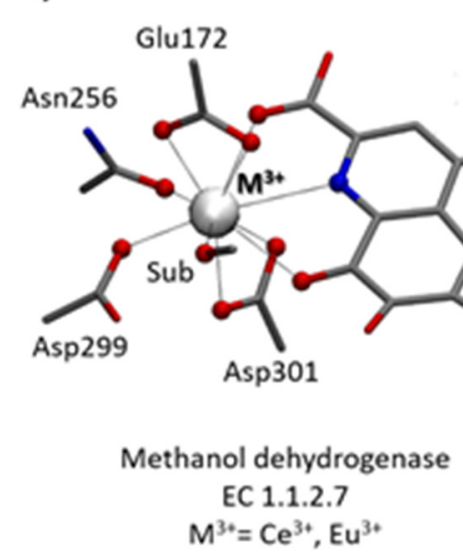

B)

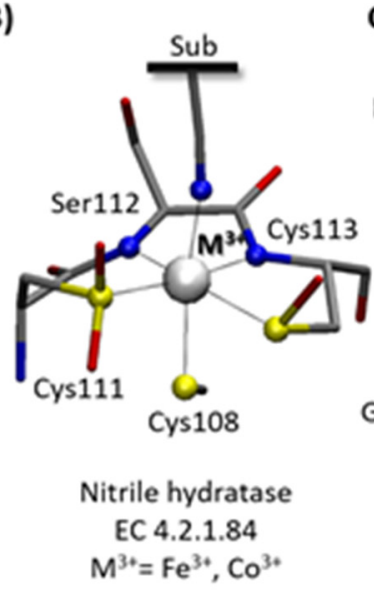

C)

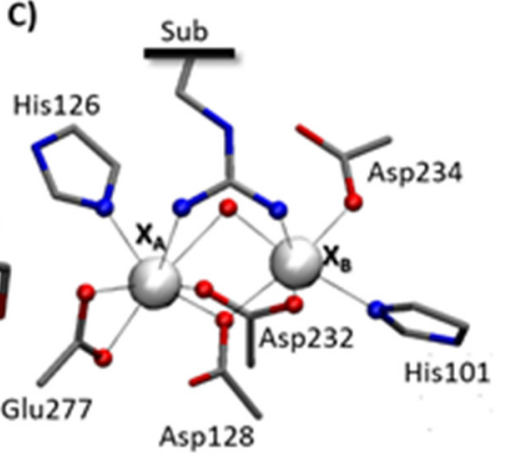

Asp128

Arginase

EC 3.5.3.1

$\mathrm{X}_{\mathrm{N}} / \mathrm{X}_{\mathrm{B}}=\mathrm{Mn}^{2+}, \mathrm{Co}^{2+}$

Figure 1. The first coordination shell of (A) methanol dehydrogenase, (B) nitrile hydratase, and (C) arginase, herein discussed.

$\mathrm{Fe}^{3+}, \mathrm{Co}^{3+}$ in nitrile hydratase and $\mathrm{Co}^{2+}, \mathrm{Mn}^{2+}$ in arginase, even if prevalent in the catalysis of redox reactions (mainly the iron metal ions), benefit from the redox-inert nature are also featured.

$\mathrm{The} \mathrm{Ce}^{3+}$ - and $\mathrm{Eu}^{3+}$-containing methanol dehydrogenase has attracted special attention since the discovery of more and more lanthanide-dependent bacteria. Bacteria as Lewis acids in the alcohol dehydrogenation especially use the earlier lanthanides [11,12].

Commonly, sulfur atoms from cysteine and methionine, nitrogen atoms from histidine, and oxygen atoms from glutamate, aspartate, and tyrosinate represent the metal-donors in proteins. The metal ion preference for a certain amino acid side chain follows the general rules of coordination chemistry. The specific chemical properties of each metal cation such as size and electron configuration dictate the ligand nature and geometry of metal-binding sites as well as their chemical neighboring residues to determine selectivity and hence, better regulation function [13]. Often different ligands can bind or chelate metals, further including water molecules [14]. Although the inner coordination shell residues play a crucial role in both metal binding and metal selectivity, it also emerged that the outer coordination shell residues may give added stability to the first shell residues dictating the specific polarity, geometry, size, plasticity of the binding site. Their consideration is therefore necessary for an appropriate description of the active site pocket $[15,16]$.

From a first glance on the Figure 1, it can be evinced that the metal binding site of every single enzyme includes the most part of the above-mentioned ligands, which in turn can coordinate different metal ions.

Many researchers [17-24] mapped the binding properties of different metal ions collecting the properties and roles of metal ions involved in catalysis for many metal-dependent enzymes. In general, redox-inert metal ions are used in enzymes to stabilize negative charges and to activate substrates 
because of their Lewis acid properties, whereas redox-active metal ions can be used both as Lewis acids and as redox centers. Although metal cations may act as Lewis acids or as redox reagents, this review focuses on Lewis acid catalysis in reactions where the metal ions work for activating the nucleophile species or the electrophile for nucleophilic attack stabilizing negative charge in the enzyme active site. Metals ions like those of copper $(\mathrm{Cu})$, iron $(\mathrm{Fe})$, lanthanides $(\mathrm{Ln})$, cobalt $(\mathrm{Co})$, zinc $(\mathrm{Zn})$, molybdenum (Mo), and tungsten $(\mathrm{W})$ are particularly important for methanotrophy $[25,26]$. In the biological systems, lanthanides usually behave like calcium analogs, and in particular, lanthanum ions (III) may replace calcium in many enzymes [27].

Quantum mechanical electronic structure methods based on the density functional theory (DFT) were used to simulate the reactions catalyzed by metalloenzymes in the framework of quantum mechanics $(\mathrm{QM})$ cluster approximation. This methodology was largely validated as a viable approach to explore enzymatic mechanisms and to give insights on the catalytic processes [28-35]. Moreover, the cluster modelling simulations represent a well-consolidated strategy to model transition states and to identify chemical mechanisms in calculations on small models of enzyme active sites as evidenced by the literature, $[28,29,33,35]$ providing also detailed and fundamental chemical insights into metal-complex geometries and electronic structures [31-37]. Therefore, the choice to examine the three investigated enzymes by using the same cluster approach helps to emphasize the effects of the metal ion substitution in the active site. In fact, the examined cases evidence that the metal ion nature can produce important catalytic consequences under equal conditions (substrate and catalytic pocket). At this purpose, the quantum-mechanical calculations can help to interpret experiments in determining likely mechanisms and in dissecting interactions, and provide a useful contribution to the analysis of individual roles in reactivity and catalysis.

$\mathrm{Ce}^{3+}$ - and $\mathrm{Eu}^{3+}$-containing enzymes were chosen as illustrative examples of chemical reactions where the metal ions can explicate different roles during the catalysis. They show as the coordination chemistry of a specific metal ion can generate structural diversity depending on the progressive decrease in ionic radius.

Moreover, in order to rationalize the effect of the metal ion substitution on the catalytic activity, the geometrical and electronic properties of the "Michaelis-Menten" enzyme-substrate complexes are also taken into account. This can reveal the electronic features of the metal ions that govern their catalytic "reactivity." The metalloenzymes examined are illustrative examples of chemical reactions where periodic relatives metal ions $\left(\mathrm{Ce}^{3+}\right.$ and $\mathrm{Eu}^{3+}$ in methanol dehydrogenase, $\mathrm{Fe}^{3+}, \mathrm{Co}^{3+}$ in nitrile hydratase, and $\mathrm{Co}^{2+}, \mathrm{Mn}^{2+}$ in arginase) can explicate different roles during the catalysis.

\section{Computational Protocol}

The Gaussian 09 program package [38] was used for all the calculations. Geometry optimizations of all the examined species along the potential energy surfaces (PES) were carried out by using various exchange-correlation functionals, in the framework of density functional theory (DFT). For the considered cases a range of exchange-correlation functionals $(\mathrm{XC})$, spacing from the standalone pure M06L [39] to the hybrid B3LYP [40,41] coupled to the Grimme's scheme (D3), [42] to the meta-hybrid BB1K and MPWB1K were employed. [43] It is important to underline that the functionals mentioned above were separately adopted in the previous works, on different systems and made impossible any generalization on their performance. For this reason, the comparative analysis about the performance of the method is not discussed and does not represent the aim of the present paper. However, this issue was widely treated in excellent papers discussing the general reliability of DFT [44-48]. For each examined system, the used XC will be specified. All-electron basis sets were used for all atoms except for the metal ions that were described by the SDD effective core potential (ECP) and the related basis set. [49] This choice ensures a high number of valence electron for the treatment of metal ions belonging to the $3 d\left(\mathrm{Mn}, \mathrm{Fe}, \mathrm{Co}\right.$, v.e. $\left.>15 \mathrm{e}^{-}\right)$and $4 f\left(\mathrm{Ce}, \mathrm{Eu}\right.$, v.e. $\left.>30 \mathrm{e}^{-}\right)$series, and allows to take into account of the scalar relativistic effects. 
The nature of minima or maxima of every stationary point on the PESs was determined by frequency calculations. Natural bond orbital (NBO) analysis [50] was performed on all the intercepted species of the investigated PESs. To estimate the effects of the protein environment, single point calculations on the gas phase optimized structures were performed by using the implicit solvation methods, such as polarizable continuum method (PCM [51], C-PCM [52]) and universal solvation method (SMD) [53], in a dielectric having a constant value $\varepsilon=4$ which represents a good choice for describing the protein surrounding [28-37,54-62].

The active site of the enzymes has been modelled following the "cluster approach," a wellconsolidated procedure in the framework of DFT, starting from the X-ray structures deposited in Protein Data Bank [28-31]. This procedure is based on the fact that usually the enzymatic reaction occurs in a specific region of the enzyme, the so-called "active site." Here, the functional groups, belonging to the side chains of first and second shell amino acid residues come into play during the catalysis. The rest of the enzyme's scaffold is considered as a matrix, in which the active site is embedded providing structural stabilization and solvation. In order to prevent the artificial expansion of the cluster, the amino acids are usually truncated at the $\alpha$-carbons and sometime simulated by opportune chemical groups. When hydrogens atoms are not present, are usually added manually following the experimental indications. The steric effects are modelled according to key-lock procedure, which consists in the freezing of the coordinates at the periphery of the model, where residue was truncated. This allows preventing large artificial movements of the groups retained in the model during the optimizations. This strategy, usually, generates imaginary frequencies presenting small values that do not affect the zero-point energy [30]. Besides, the approach maces the system slightly rigidly, generating negligible differences in the description of energetics; previous studies on different enzymes [54-62] indicate that this does not alter the conclusions about the reaction mechanisms.

In addition, for the systems here presented, the QM models have been built up considering the metal centers and 110-170 atoms belonging to cofactors and amino acids characterizing the active site. This choice represents a good strategy because guaranties a good balance between reliability of the model and the computational time requested to perform the simulation $[28,35,36]$. Anyway, the versatility of the cluster model resides also in the possibility to build up bigger systems, up to 400 atoms, as reported in recent works [32,33].

Other valid methods have been adopted to investigate the different properties related to the metalloenzymes, like quantum mechanics/molecular mechanics (QMMM), electron valence bond (EVB), and Car-Parrinello molecular dynamics (CPMD) methods, that are not discussed here, and we remand any deepening to complete and consultable reviews [63-68].

\section{3. $\mathrm{Ce}^{3+}$ and $\mathrm{Eu}^{3+}$ Methanol Dehydrogenase}

Quinoproteins are a class of dehydrogenases (E.C. 1.1.2.7) that bear a Lewis acid metal cation in addition to the redox PQQ cofactor in the active site. They were first characterized in methylotrophic bacteria with several evidences reporting their wide distribution nature [69]. MDH oxidizes a wide range of primary alcohols (Scheme 1) but has especially high affinity for methanol. The first studies on this enzyme and its reaction mechanism date back more than 40 years [69-80].

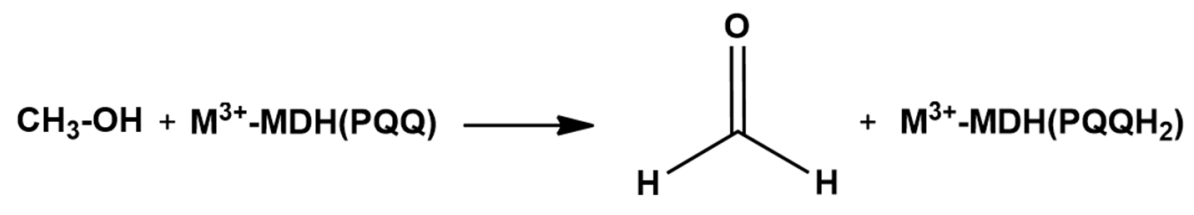

Scheme 1. The dehydrogenation of methanol.

The enzyme is, generally, calcium dependent [73-80]. Recently, a bacterium, of XoxF type (Methylacidiphilum fumariolicum SolV), containing early lanthanides (Lns = La, Ce, Pr, and Nd)-dependent $\mathrm{MDH}$ instead of calcium [81], has been discovered in the acidic hot water spring of a volcano in Italy. 
because of their modest abundance, Lns, were considered for long time to be biologically inert but the further discovery of their presence in a novel MDH (methylotrophic bacterium Methylobacterium radiotolerans), [75] increased the focus on them.

Nevertheless, the function and activity of Lns in the human organism is still the subject of controversy, since the common opinion is that trivalent lanthanum ions behave very similarly to calcium ions in the biological systems substituting $\mathrm{Ca}^{2+}$ in many proteins, [82] including enzymes [83] and cell membranes $[84,85]$.

XoxF sequences share almost $50 \%$ amino acid residues with MxaF, the mostly studied and well-characterized two-subunit methanol dehydrogenase, which contains PQQ and $\mathrm{Ca}^{2+}$ ion as cofactors in its catalytic center [8,9]. Interestingly the presence in the active site of a metal ion with larger size and higher charge with respect to those of the calcium ion requires a further amino acid residue, the Asp301, to balance the excess of positive charge of the metal center [86-88]. The PQQ cofactor interacting with alcohol substrate accepts formally two electrons and two protons giving rise to the corresponding aldehyde and the reduced $\mathrm{PQQH}_{2}$ form $[10,89]$.

The MDH that uses different metal ions are an example of condition promiscuity $[83,84,86]$.

The studies on MDH isolated from the Methylacidiphilum fumariolicum SolV bacterium, allowed to identify in the active site of enzyme the most abundant lanthanide, the cerium ion [82]. Even more recently, further investigations on the same bacterium revealed that europium ion can be present in its active center [90].

The action mechanism of Lns-containing MDH is still an open question because of the recent discoveries [91-100].

To contribute to the ongoing discussion, we are going to illustrate results of our comparative study on the reaction mechanism of cerium and europium containing MDH. The results were obtained employing a quantum chemical investigation using the cluster methodology as mentioned in computational protocol section.

The catalytic behavior of the cerium- and europium-containing enzyme, along with the analysis of the structural, electronic properties, and of the charges distribution were examined. The different lanthanides, while presenting similar ionic radii due to lanthanide contraction effect and coordination number (C.N.), can equally generate different effects in the active site of MDH [101-103].

The X-ray structure of the Xoxf-type natural cerium-dependent MDH (PDB:4MAE, $1.6 \AA$ ) [81] and crystals report of the europium-dependent enzyme without substrate (PDB:6FKW, $1.4 \AA$ ) [90] were used for modelling the Michaelis-Mentens complex (ES) starting structures, for $\mathrm{Ce}^{3+}$ - and $\mathrm{Eu}^{3+}$ enzymes, respectively, depicted in Figure 2.

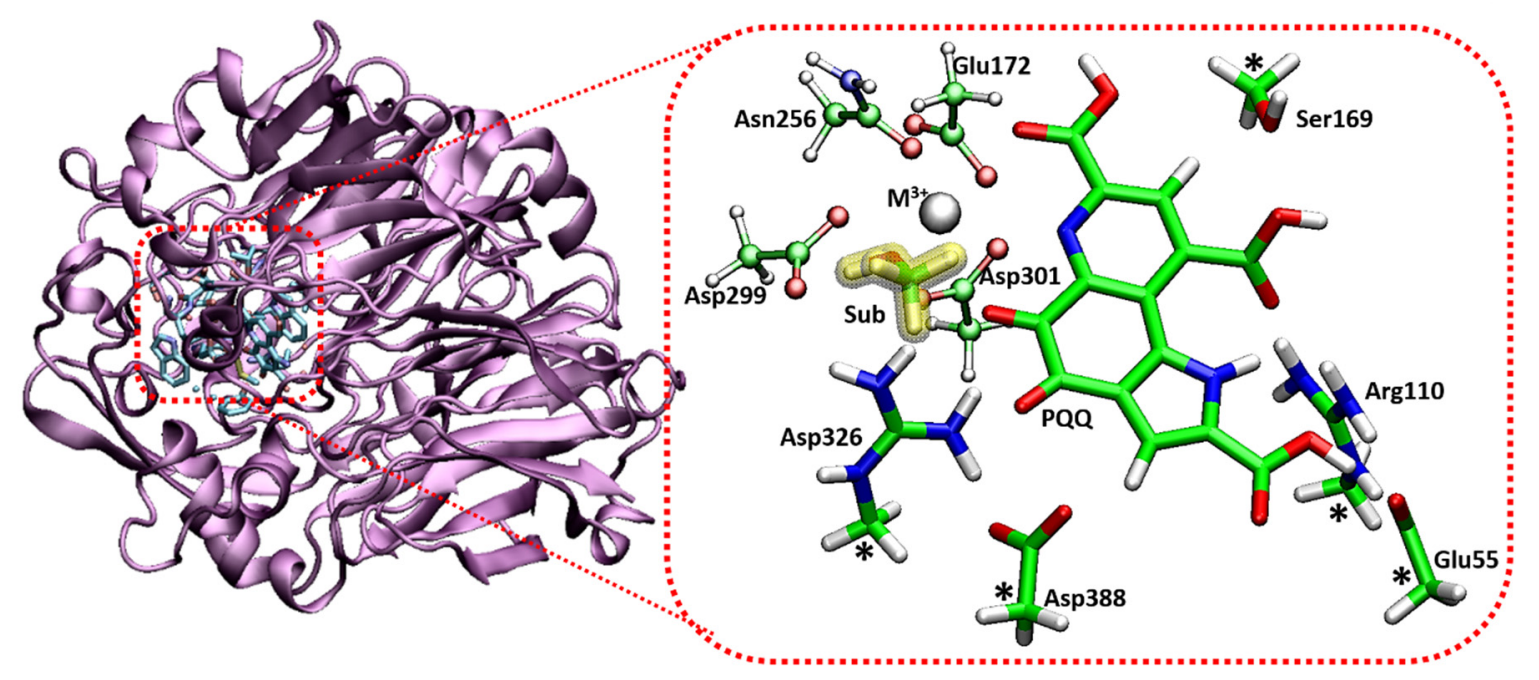

Figure 2. Quantum mechanics (QM) cluster model of $\mathrm{M}^{3+}-\mathrm{MDH}\left(\mathrm{M}^{3+}=\mathrm{Ce}^{3+}, \mathrm{Eu}^{3+}\right)$ active site. Stars indicate the locked atoms frozen during the calculations. 
The obtained cluster includes the amino acid residues of the inner coordination shell of the metal ions (Glu172, Asn256, Asp299, and Asp301), the cofactor PQQ and Glu55, Arg110, Ser169, Arg326, and Asp388 residues of the outer coordination shell that could form hydrogen bonds with the cofactor. The methanol substrate is coordinated to the metal center by the hydroxyl group. The model consists of 113 atoms, and has a total charge of zero.

Among the various mechanisms proposed for MDH enzymes over the years $[8-10,74,75,86,87$, $89,91,98,99,104-107]$, we have chosen to explore that reported in the Scheme 2 that revealed to be the most reliable one as proposed in previous studies [100,105-107].

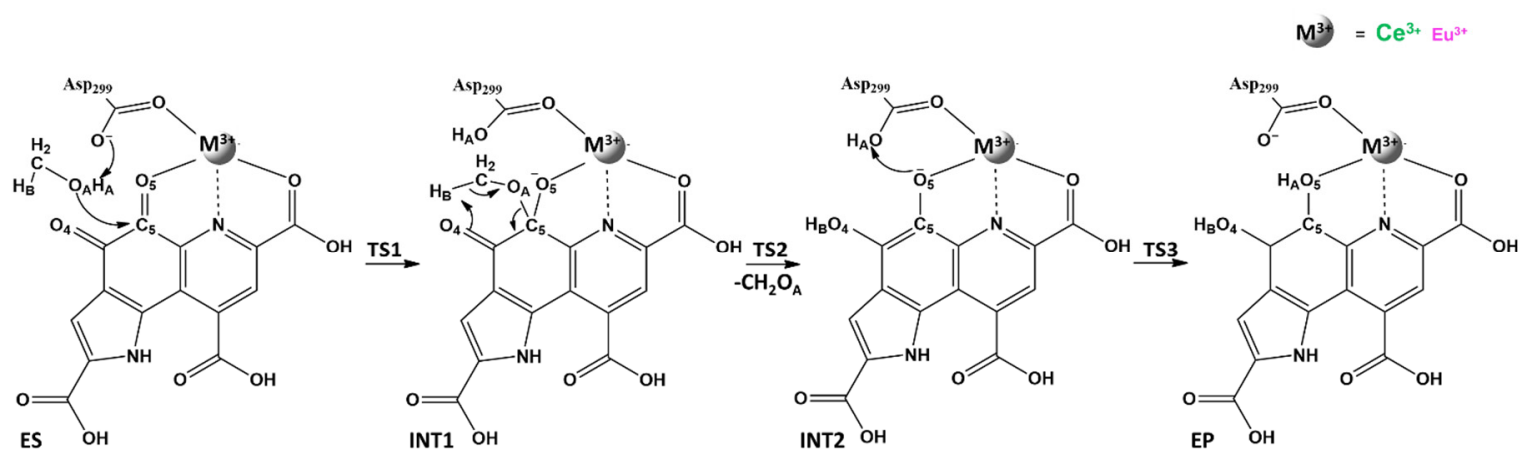

Scheme 2. The addition-elimination-protonation mechanism investigated for $\mathrm{M}^{3+}-\mathrm{MDH}$ $\left(\mathrm{M}^{3+}=\mathrm{Ce}^{3+}, \mathrm{Eu}^{3+}\right)$.

The optimized structures of the ES complex (see Figure 3) are in agreement with the experimental counterpart $[81,90]$. As generally occur in the lanthanides chemistry, cerium and europium ions show a coordination number equal to 9 [101]. The PQQ acts as bidentate ligand toward metals through its $\mathrm{O} 7$ and $\mathrm{O} 5$ atoms, with distances of $2.73 \AA$ and $2.96 \AA$, for $\mathrm{Ce}^{3+}-\mathrm{MDH}$, and $2.69 \AA$ and $2.83 \AA$, for $\mathrm{Eu}^{3+}-\mathrm{MDH}$.

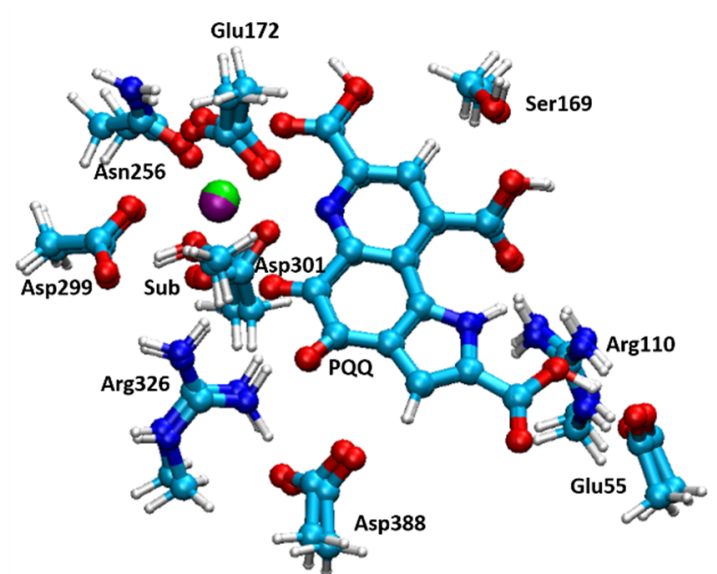

Figure 3. Superposition of B3LYP-D3/6-31+G(d,p)|SDD optimized geometries of ES complexes for the $\mathrm{Ce}^{3+}$-(green) and $\mathrm{Eu}^{3+}-\mathrm{MDH}$ (purple).

The PES for both $\mathrm{Ce}^{3+}-\mathrm{MDH}$ and $\mathrm{Eu}^{3+}-\mathrm{MDH}$ enzymes in protein environment $(\varepsilon=4)$ is reported in Figure 4. 


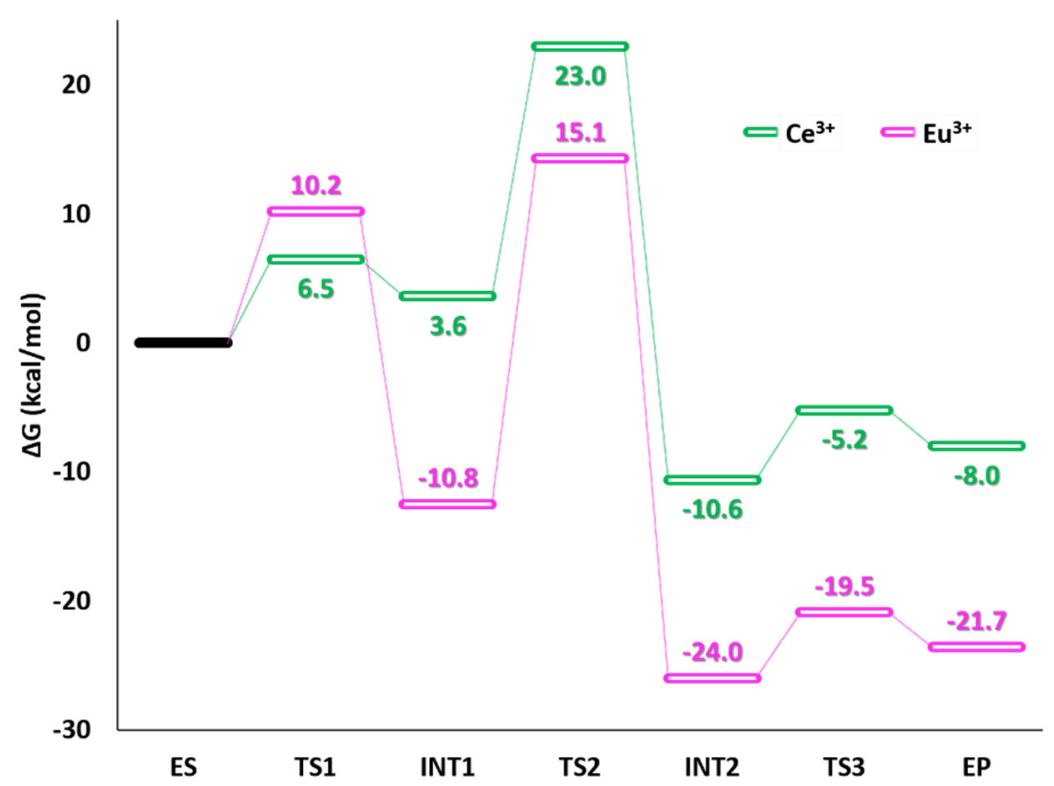

Figure 4. C-PCM $(\varepsilon=4) / B 3 L Y P-D 3 / 6-311+G(2 d, 2 p) \mid S D D$ calculated energy profiles for Ce ${ }^{3+}-\mathrm{MDH}$ [105] and $\mathrm{Eu}^{3+}-\mathrm{MDH}[106]$.

In the first step of the mechanism, as suggested by NBO analysis on $\mathrm{Ce}^{3+}-\mathrm{MDH}$ and $\mathrm{Eu}^{3+}-\mathrm{MDH}$, the electron-withdrawing effect of the metal ion plays a crucial role in making the negative charge of carbonyl carbon C5 of the PQQ higher than that assessed for the free PQQ (0.53 versus $0.46 \mid \mathrm{el})$.

The nucleophilic attack of the coordinated methanol -OH group having its lone pair oriented toward the PQQ is thus facilitated and the proton is soon transferred to the Asp299 base.

The TS1 describes the concerted nucleophilic attack and the proton transfer as revealed by the analysis of the imaginary frequency $\left(281 i \mathrm{~cm}^{-1}\right.$, in $\mathrm{Ce}^{3+}-\mathrm{MDH}$, and $199 i \mathrm{~cm}^{-1}$, in $\left.\mathrm{Eu}^{3+}-\mathrm{MDH}\right)$. Both metalloenzymes present the proton $\mathrm{H}_{\mathrm{A}}$ lying at $1.04 \AA \AA^{\circ}$ and $1.00 \AA \AA^{6}$ from the Asp299, at $1.54 \AA$ And $1.62 \AA$ from the methanol and at $1.89 \AA$ Á and $1.63 \AA$ Á from $\mathrm{C} 5$ atom of PQQ which assumes a tetrahedral-like structure, in the case of $\mathrm{Ce}^{3+}$ - and $\mathrm{Eu}^{3+}-\mathrm{MDH}$ respectively, as reported in Table 1.

Table 1. Geometrical parameters obtained for the isolated stationary point along the reaction mechanism of $\mathrm{Ce}^{3+}-\mathrm{MDH}$ and $\mathrm{Eu}^{3}+-\mathrm{MDH}$ (in parenthesis) $[105,106]$. Data not available, due to the release of the product, are indicated with "n.a." All values are in $\AA$.

\begin{tabular}{cccccccc}
\hline Distances & ES & TS1 & INT1 & TS2 & INT2 & TS3 & EP \\
\hline $\mathbf{M}^{3+}-\mathbf{O}$ & $2.57(2.45)$ & $2.85(2.83)$ & $2.84(2.83)$ & $4.83(2.89)$ & $5.73(4.82)$ & n.a. & n.a. \\
$\mathbf{C}_{\mathbf{P Q Q}}-\mathbf{O}_{\mathbf{A}}$ & $4.00(3.72)$ & $1.89(1.63)$ & $1.48(1.48)$ & $2.37(1.74)$ & $4.15(3.56)$ & n.a. & n.a. \\
$\mathbf{O}_{\mathbf{A s p 2 9 9}-\mathbf{H}_{\mathbf{A}}}$ & $1.52(1.60)$ & $1.04(1.00)$ & $1.00(0.99)$ & $1.00(1.00)$ & $1.02(1.04)$ & $1.12(1.11)$ & $1.51(1.37)$ \\
$\mathbf{O}_{\mathbf{P Q Q}}-\mathbf{H}_{\mathbf{B}}$ & $2.84(2.84)$ & $3.16(3.21)$ & $2.93(3.03)$ & $1.35(1.24)$ & $0.97(0.97)$ & $0.99(0.97)$ & $0.98(0.97)$ \\
$\mathbf{O}_{\mathbf{P Q Q}}-\mathbf{H}_{\mathbf{A}}$ & $3.40(3.39)$ & $3.82(2.83)$ & $2.76(2.75)$ & $1.65(2.34)$ & $1.54(1.47)$ & $1.22(1.25)$ & $1.02(1.05)$ \\
\hline
\end{tabular}

TS1 lies at $6.5\left(\mathrm{Ce}^{3+}-\mathrm{MDH}\right)$ and $10.2 \mathrm{kcal} / \mathrm{mol}\left(\mathrm{Eu}^{3+}-\mathrm{MDH}\right)$ above the respective ESs (see Figure 4) and gives rise to intermediate (INT1) which is found at $3.6 \mathrm{kcal} / \mathrm{mol}$ and $-10.8 \mathrm{kcal} / \mathrm{mol}$, for ceriumand europium-containing MDH, respectively.

In INT1 the bond between the substrate oxygen and C5 of the PQQ (1.48 Á) is definitely formed, in both metalloenzymes. Here the $\mathrm{H}_{\mathrm{B}}$ of the substrate methyl group and the $\mathrm{O} 4$ of PQQ are at a distance of $2.93 \AA$ ( $\left(\mathrm{Ce}^{3+}-\mathrm{MDH}\right)$ and $3.03 \AA$ ( $\left(\mathrm{Eu}^{3+}-\mathrm{MDH}\right)$ from each other. In the next step, the transfer of $\mathrm{H}_{\mathrm{B}}$ from the methyl group to the $\mathrm{O} 4$ and the breaking of the $\mathrm{O}_{\mathrm{A}}-\mathrm{C} 5$ takes place simultaneously realizing the partial PQQ reduction. This can be confirmed by the TS2 structure in which the migrating $\mathrm{H}_{B}$ is halfway between the donor and acceptor atoms and the $\mathrm{O}_{A}-\mathrm{C} 5$ is elongated by about 0.9 in 
the case of $\mathrm{Ce}^{3+}-\mathrm{MDH}$, and of $0.4 \AA$, in the case of the $\mathrm{Eu}^{3+}-\mathrm{MDH}$, compared to the values it had in INT1. For this reason, the event occurs at the imaginary frequency of $989 i \mathrm{~cm}^{-1} 852 i \mathrm{~cm}^{-1}$ respectively. In INT2, the reaction product appears to be already formed.

In fact, formaldehyde lies practically outside of the reaction site, even if it is retained in the catalytic cavity by the H-bond with Ser169 (2.02 Á and $1.94 \AA$ Á). The reaction continues until to the accomplishment of the cofactor reduction from $\mathrm{PQQH}$ to $\mathrm{PQQH}_{2}$. The protonated Asp299 donates its proton to $\mathrm{C} 5-\mathrm{O} 5$ hydroxylate group $(\mathrm{PQQH})$ giving back its catalytically active form for another cycle. The hydrogen transfer (TS3) requires $5.4 \mathrm{kcal} / \mathrm{mol}$ and $5.5 \mathrm{kcal} / \mathrm{mol}$, respectively. The EP final species shows that the $\mathrm{OH}$ groups of the $\mathrm{PQQH}_{2}$ are involved in two strong $\mathrm{H}$-bonds with the Asp299 residue $\left(\mathrm{O}_{\mathrm{Asp} 299}-\mathrm{H}_{\mathrm{A}}=1.50 \AA\right.$ and $\mathrm{O}_{\mathrm{Asp} 299}-\mathrm{H}_{\mathrm{B}}=1.94 \AA$ in $\mathrm{Ce}^{3+}-\mathrm{MDH} ; \mathrm{O}_{\mathrm{Asp} 299}-\mathrm{H}_{\mathrm{A}}=1.38 \AA$ and $\mathrm{O}_{\mathrm{Asp} 299}-\mathrm{H}_{\mathrm{B}}=$ $2.13 \AA$ in $\left.\mathrm{Eu}^{3+}-\mathrm{MDH}\right)$ giving rise to a shortening of the three coordination bonds with the metal ion. EP lies at $8.0 \mathrm{kcal} / \mathrm{mol}\left(\mathrm{Ce}^{3+}-\mathrm{MDH}\right)$ and $21.7 \mathrm{kcal} / \mathrm{mol}\left(\mathrm{Eu}^{3+}-\mathrm{MDH}\right)$ below the ESs suggesting favorable thermodynamics for the process.

The rate-determining step for the catalytic cycle is TS2 for both enzymes. NBO analysis indicates that the $\mathrm{Ce}$ and Eu ions oxidation state does not change during the whole reduction cycle of $\mathrm{PQQ}$ cofactor.

The obtained PES was compared with that of calcium-containing MDH in our previous investigation [107]. One obvious fact, which we have widely supported in our previous works [105,106], is that despite the different charge, size, and number of coordinated residues of the ions, the topology of the active site as well as the course of the catalytic cycle for the two enzymes is very similar. This striking similarity between lanthanides and $\mathrm{Ca}^{2+}$ ions, is, as already mentioned before, widely reported in the literature [90-100,105,106].

In both enzymes, TS2 barrier represents the rate limiting step. In relation to this step, the catalytic activity of calcium-containing enzyme is slightly better with respect to the cerium one. On the contrary, the stronger Lewis acidity of the $\mathrm{Ce}^{3+}$ compared to that of $\mathrm{Ca}^{2+}$ influences the first step of the mechanism where the lanthanide ion, making the $\mathrm{C} 5$ more electrophile, intensifies the nucleophilic nature of the $\mathrm{OH}$ moiety in the substrate more than calcium. Therefore, the first barrier (TS1) is more favorable in $\mathrm{Ce}^{3+}-\mathrm{MDH}$ than in $\mathrm{Ca}^{2+}-\mathrm{MDH}[105,107]$.

As in the case of $\mathrm{Ce}^{3+}$ (ionic radius $1.20 \AA$ ), $\mathrm{Eu}^{3+}$ (ionic radius $1.12 \AA$ ) shows a coordination number equal to 9 . However, looking at the values of the metal coordination distances in the ES complex, it can be seen that because of the increase in the atomic number a small contraction of the bond lengths is observed (see Table 2). This behavior is in agreement with the "lanthanide contraction effect," [101-103] a well-known property of the $4 f$ elements. According to this key aspect of the lanthanides chemistry, the decrease of ionic radius is related to the increase of atomic number along the series, because of the effective nuclear charge experienced by the $4 f$ outer electrons, caused by the incomplete shielding of the $5 s$ and $5 p$ electrons [101].

Table 2. Comparison between bond distance in first coordination sphere of $\mathrm{M}^{3+}-\mathrm{MDH}\left(\mathrm{M}^{3+}=\mathrm{Ce}, \mathrm{Eu}\right)$ obtained at B3LYP-D3/6-31G+(d,p)|SDD level of theory $[105,106]$. All values are in $\AA$.

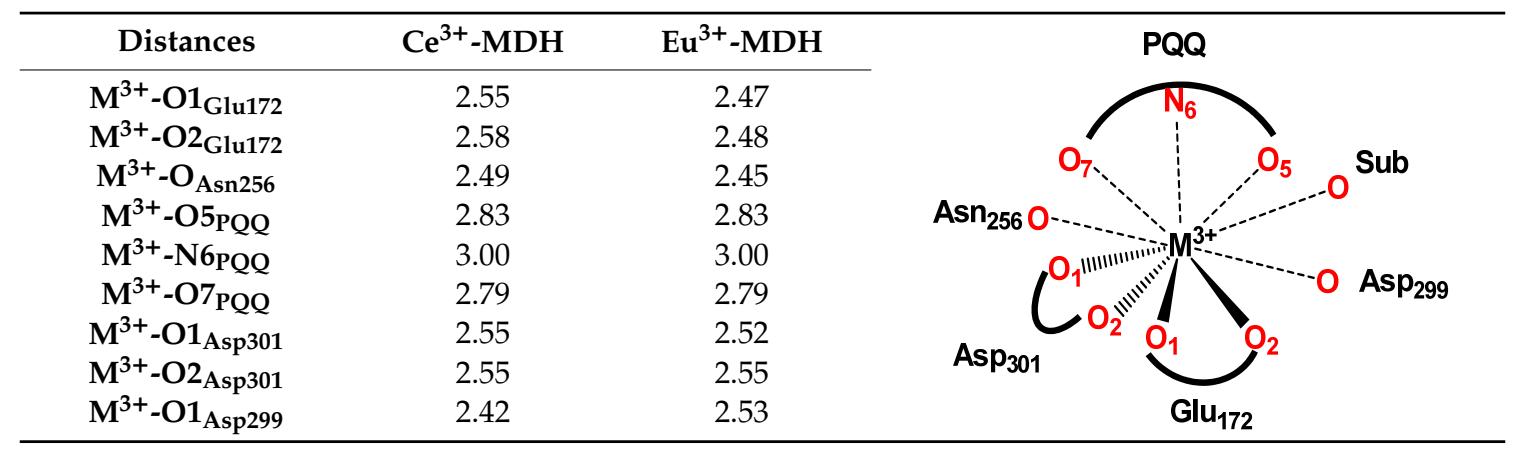

So, the different behavior of $\mathrm{Ce}^{3+}$ - and $\mathrm{Eu}^{3+}$-dependent methanol dehydrogenases can be ascribed mainly to their different strength as Lewis acids. From NBO analysis for the ES complexes of both 
lanthanides, a more negative charge on the substrate oxygen for the $\mathrm{Ce}^{3+}-\mathrm{MDH}$ with respect to the $\mathrm{Eu}^{3+}-\mathrm{MDH}$ is obtained. As aforesaid, this is very important because the polarization induced on the oxygen of the substrate's OH group, facilitates the proton transfer and nucleophilic addition to the O5 oxygen of the PQQ cofactor, by ensuring that the charge value on O5 atom of the PQQ cofactor remains almost the same in both cases. The better nature of Lewis acid of $\mathrm{Ce}^{3+}$ with respect to $\mathrm{Eu}^{3+}$ was confirmed by frontiers orbital analysis of the enzyme-substrate complexes. In fact, the energetic gap separating the HOMO from LUMO in the ES complex of $\mathrm{Ce}^{3+}-\mathrm{MDH}$ is smaller by $0.84 \mathrm{eV}$ than that of the same orbitals in the $\mathrm{Eu}^{3+}-\mathrm{MDH}$. So, the different behavior of $\mathrm{Ce}^{3+}$ - and $\mathrm{Eu}^{3+}$-dependent methanol dehydrogenases can be ascribed mainly to their different strength as Lewis acids.

\section{Low Spin $\mathrm{Fe}^{3+}$ and $\mathrm{Co}^{3+}$ Nitrile Hydratase}

Nitrile hydratase (NHase, E.C. 4.2.1.84) from Pseudomonas putida [108], Rhodococcus rhodochrous J1 [109,110], and Pseudonocardia Thermophila JM 3095 [111] microorganisms represents an example of proteins studied and adopted on a large scale in the chemical synthesis. Nitrile hydratases catalyze the hydrolysis of organic nitriles, as reported in Scheme 3, in their amides, [112-114] which can be further transformed by the amylases, in ammonia and carboxylic acids [115] in an eventual second step.

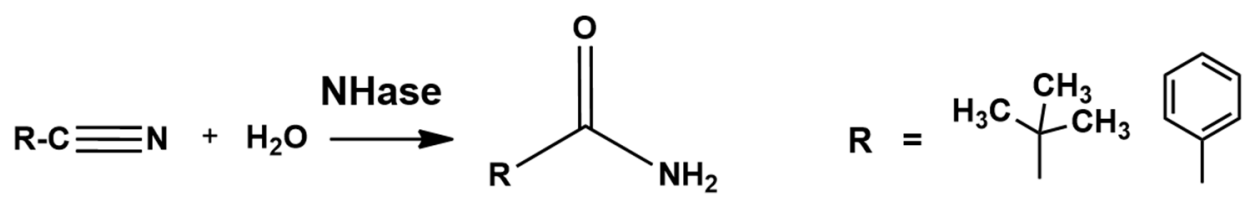

Scheme 3. The hydration of organic nitrile.

The enzymes belonging to NHase family are of supreme importance for the production of relevant compounds, as acrylamide and nicotinamide [112,116-119].

Metal ion in iron-type and cobalt-type NHases are in a nonheme and a noncorrinoid contest, respectively. As far as cobalt ion is concerned, this is not usual because, in biochemistry, it is generally found in a corrin ring, such as in vitamin B12.

Both mentioned NHases exhibit similarities. In fact, low spin multiplicities, for $\mathrm{Fe}^{3+}(\mathrm{S}=1 / 2)$ and for $\mathrm{Co}^{3+}(\mathrm{S}=0)$ in the catalysis have been measured, and the same reaction mechanism has been hypothesized. In addition, their primary and secondary structures are widely conserved tetramer of $92 \mathrm{kDa}$ [120]. The ligands of the metal ion belong to the $\alpha$ subunit. The cation is located at the interface between $\alpha$ and $\beta$ subunits. In this cavity, its coordination sphere is composed by an axial cysteine thiolate, two equatorial backbone nitrogen, and two equatorial sulfur. In this last case, the atoms belong to post-translationally modified cysteines: the cysteine-sulfenic (Cys-SOH) and cysteine-sulfinic $\left(\mathrm{Cys}-\mathrm{SO}_{2} \mathrm{H}\right)$ acids. A labile axial water molecule completes the hexa-coordination [121].

Both Cys $-\mathrm{SO}_{2} \mathrm{H}$ and Cys- $\mathrm{SOH}$ are deprotonated [122]. The oxidized state of cysteines was proven essential for the catalysis, because in presence of two Cys- $\mathrm{SO}_{2} \mathrm{H}$ catalytic activity was not registered [123]. In addition, the oxygenation of cysteines [123] enhances the Lewis acid character of the metals, removing electron density from the metallic ions.

It is known that $\mathrm{Fe}^{3+}-\mathrm{NH}$ ases shows higher affinity to aliphatic nitriles as substrates, while the $\mathrm{Co}^{3+}-\mathrm{NH}$ ases to aromatic compounds. Experimental EPR measures are available [124] only for $\mathrm{Fe}^{3+}$-type NHase, because the $d^{6}$ low spin electronic configuration of $\mathrm{Co}^{3+}-\mathrm{NHase}$ enzymes does not allow their inspection by EPR spectroscopy. However, other spectroscopic data are available for $\mathrm{Co}^{3+}-\mathrm{NH}$ ases [124].

NHases are capable to work under physiological conditions and for this reason are considered good biocatalysts in preparative organic species $[125,126]$. The detailed knowledge of their catalytic mechanism can provide useful insights. With this in mind, in order to understand the role of the metal ions ( $\mathrm{Fe}$ and $\mathrm{Co}$ ) and to elucidate the catalytic mechanisms of both $\mathrm{Fe}^{3+}-$ and $\mathrm{Co}^{3+}-\mathrm{NHases,}$ a DFT-based comparative study has been undertaken. 
The active site model was obtained using the X-ray structure derived from the bacterial culture of Pseudonocardia Thermophila JCM 3095 ( $\mathrm{Co}^{3+}-\mathrm{NHase}$, pdb code: 1IRE), [127] and from Rhodococcus erythropolis $N 771$ ( $\mathrm{Fe}^{3+}-\mathrm{NHase}$, pdb code: 2ZPE) [128].

In particular, the consequent model for $\mathrm{Co}^{3+}$-Type NHase consists of 116 atoms with a total charge equal to +1 (see Figure 5). The trivalent cobalt ion is surrounded by $\alpha$ Cys108, $\alpha$ Cys111, $\alpha$ Ser112, $\alpha$ Cys113 amino acids belonging to the first coordination sphere, and $\beta$ Arg52, $\beta \operatorname{Arg} 157, \beta$ Leu48, $\beta$ Tyr68 of the second coordination sphere [127]. Two water molecules (w1 and w2), present in the X-ray structure, playing an active role in TS2 and TS3 steps, as will be lately highlighted, are included in the model.

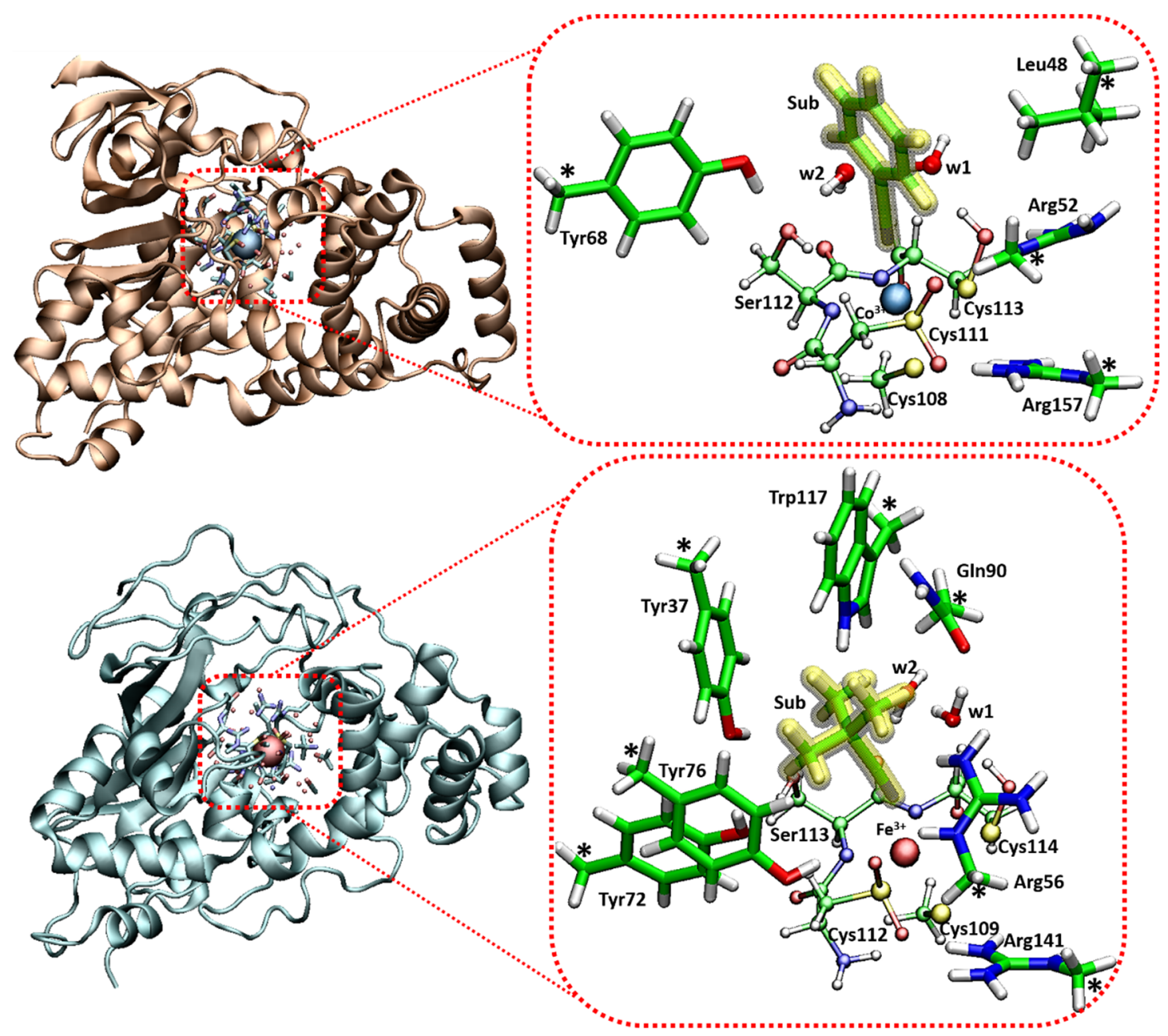

Figure 5. QM cluster model of $\mathrm{Co}^{3+}-$ (top) and $\mathrm{Fe}^{3+}-\mathrm{NHase}$ active site (bottom), including the benzonitrile and pivalonitrile substrates, respectively. Stars indicate the locked atoms frozen during the calculations.

Part of the main chain of $\alpha$ Cys111, $\alpha$ Ser112, and $\alpha$ Cys113 amino acid residues was retained in the model. Instead, the $\beta$ Tyr68, $\alpha$ Cys108, the two $\beta$ Arg52 and $\beta$ Arg157, and $\beta$ Leu48 residues were reduced to a phenol ring, a $\mathrm{CH}_{3} \mathrm{~S}^{-}$, a $\left[\mathrm{CH}_{3} \mathrm{NHC}\left(\mathrm{NH}_{2}\right)\right]^{+}$, and a $\mathrm{CH}\left(\mathrm{CH}_{3}\right)_{3}$ ter-butyl group, respectively. The benzonitrile was chosen based on the $\mathrm{Co}^{3+}-\mathrm{NH}$ ase specificity and oriented in a similar way as that of the enzyme-inhibitor complex $\mathrm{Co}^{3+}-\mathrm{NHase}$-phenylboronic acid [111]. $\mathrm{For} \mathrm{Fe}^{3+}$-Type NHase the obtained model contains 164 atoms with total charge equal to +1 and includes $\beta$ Tyr37, $\beta$ Arg56, $\beta \operatorname{Tyr} 72, \beta \operatorname{Tyr} 76, \beta \operatorname{Arg} 141, \alpha \mathrm{Gln} 90$, and $\alpha \operatorname{Trp} 117$. For both Fe ${ }^{3+}-$ and $\mathrm{Co}^{3+}-\mathrm{NH}$ ases the residues of the first coordination shell are the same (see Figure 5). In addition, in this case two water molecules are present. The substrate is the pivalonitrile. 
Despite the catalytic reaction of the nitrile hydrolysis by both $\mathrm{Fe}^{3+}-$ and $\mathrm{Co}^{3+}-\mathrm{NHases}$ was extensively studied at the experimental level, [111,122,124,128-130] its working mechanism remains poorly understood. At theoretical level, exhaustive studies exist only for the $\mathrm{Fe}^{3+}-\mathrm{NH}$ ase enzyme $[105,114-118]$. Based on experimental suggestions $[109,131]$ the mechanism has been explored as depicted in Scheme 4 for both $\mathrm{Fe}^{3+}-$ and $\mathrm{Co}^{3+}$ NHases, in which direct coordination of the nitrile to the metal during the catalytic hydration reaction is supported [109]. The PES in protein medium for both investigated systems are reported in Figure 6.

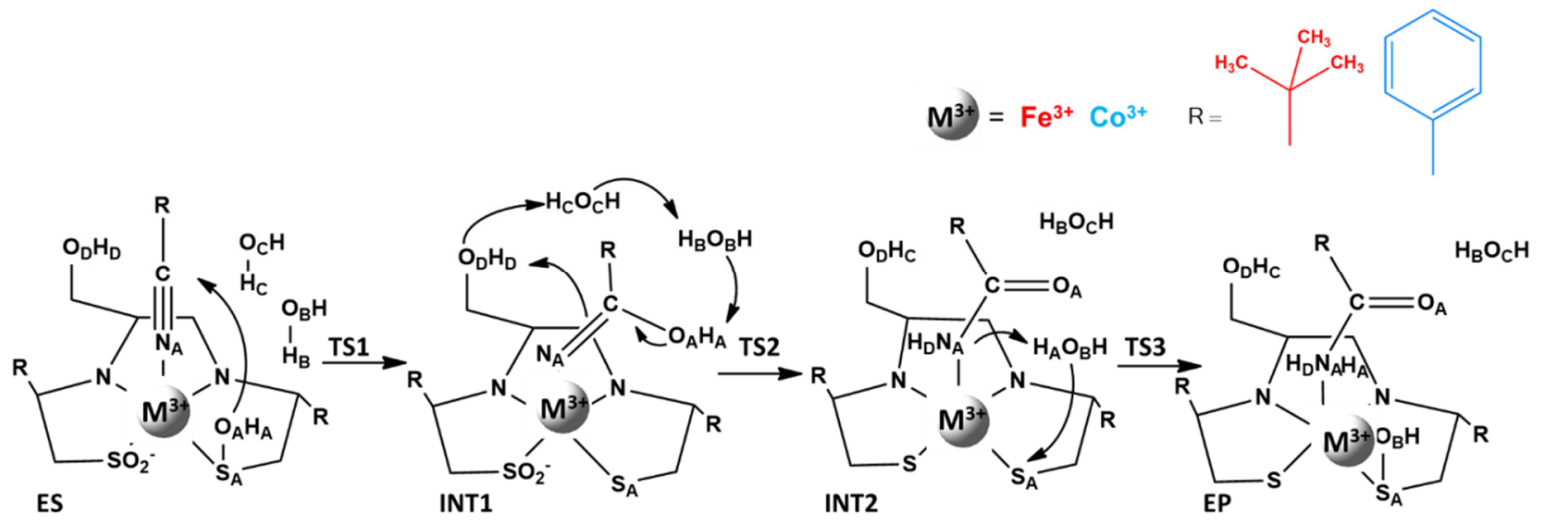

Scheme 4. The proposed mechanism for the nitrile hydrolysis catalyzed by $\mathrm{Co}-$ and Fe-NHase enzymes.

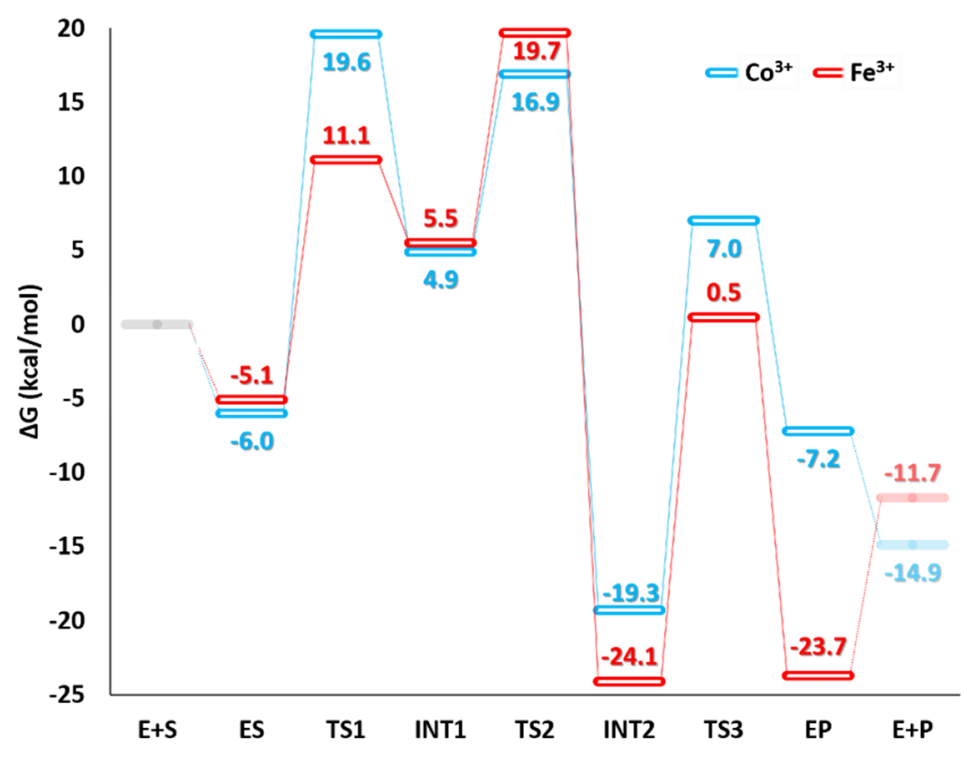

Figure 6. $\operatorname{SMD}(\varepsilon=4) / \mathrm{M} 06 \mathrm{~L} / 6-311+\mathrm{G}(2 \mathrm{~d}, 2 \mathrm{p}) \mid \mathrm{SDD}$ energy profiles for the conversion of nitrile to amide catalyzed by $\mathrm{Co}^{3+}$ - and by $\mathrm{Fe}^{3+}-\mathrm{NH}$ ase enzymes [132].

In the preliminary step of the study, the lowest-energy spin state of ES for $\mathrm{Co}^{3+}-\mathrm{NH}$ ase enzyme was determined. The analysis of the three possible values of 1,3 , and 5 of $2 S+1$ multiplicity proposed the singlet as the most stable state, in agreement with the experimental indication [111,122].

In the ES complex, the top of the catalytic cavity, represented by the amino acid residues of metal ion external coordination sphere ( $\beta$ Leu48 and $\beta$ Tyr68), allows the insertion of the benzonitrile substrate that moves the water molecule w1 outside the coordination sphere coordinating the metal ion with a distance of $1.99 \AA$. At $4.23 \AA$ from $\mathrm{Co}^{3+}, \mathrm{w} 1$ water molecule establishes a hydrogen bond with the w2 water molecule (bond length is $1.74 \AA$ ). Together, w1 and w2 give rise to a network of hydrogen bonds with the -OH groups of $\alpha \operatorname{Ser} 112$ and $\beta$ Tyr68 and the nitrogen atom of the substrate, 
as evidenced by the distances of $1.96,1.84$, and $2.41 \AA$, respectively, in Table 3 that stabilize the ES complex $(6.0 \mathrm{kcal} / \mathrm{mol}$ below the reagents). The TS1 transition state describes the nucleophilic attack on the nitrile carbon by the $-\mathrm{OH}$ group of the $\alpha \mathrm{Cys} 113-\mathrm{S}-\mathrm{OH}$, which, as supposed in a previous work, [133] acts as nucleophile without the activation by a base. This result is however at odds with older suggestions [134] that indicate as nucleophile the $-\mathrm{OH}$ group of the serine residue.

Table 3. Main geometrical parameters (having Scheme 4 as reference) obtained for the stationary points from the PES of $\mathrm{Co}^{3+}$-NHase and $\mathrm{Fe}^{3+}$-NHase (in parenthesis) [132]. All values are in $\AA$.

\begin{tabular}{cccccccc}
\hline Distances & ES & TS1 & INT1 & TS2 & INT2 & TS3 & EP \\
\hline $\mathbf{M}^{3+}-\mathbf{N}_{\mathbf{A}}$ & $2.00(2.04)$ & $1.89(1.88)$ & $1.87(1.88)$ & $1.87(2.12)$ & $1.89(1.91)$ & $2.07(2.10)$ & $3.87(3.99)$ \\
$\mathbf{C}-\mathbf{O}_{\mathbf{A}}$ & $3.53(3.94)$ & $2.01(1.79)$ & $1.41(1.36)$ & $1.36(1.37)$ & $1.28(1.27)$ & $1.23(1.22)$ & $1.26(1.26)$ \\
$\mathbf{N}_{\mathbf{A}}-\mathbf{H}_{\mathbf{D}}$ & $2.37(3.43)$ & $2.22(2.10)$ & $1.83(3.20)$ & $1.71(1.29)$ & $1.02(1.02)$ & $1.02(1.02)$ & $1.01(1.01)$ \\
$\mathbf{O}_{\mathbf{B}}-\mathbf{H}_{\mathbf{A}}$ & $1.70(1.69)$ & $2.05(1.73)$ & $1.63(1.51)$ & $1.14(1.57)$ & $0.98(0.98)$ & $1.29(1.35)$ & $1.01(1.03)$ \\
$\mathbf{O}_{\mathbf{C}}-\mathbf{H}_{\mathbf{B}}$ & $1.69(1.83)$ & $1.83(4.23)$ & $1.63(1.82)$ & $1.25(1.49)$ & $0.98(0.98)$ & $1.05(1.01)$ & $0.96(0.97)$ \\
$\mathbf{O}_{\mathbf{D}}-\mathbf{H}_{\mathbf{C}}$ & $1.96(4.00)$ & $2.26(1.81)$ & $2.00(1.93)$ & $1.75(2.03)$ & $0.97(0.99)$ & $0.96(0.97)$ & $0.98(0.98)$ \\
$\mathbf{N}_{\mathbf{A}}-\mathbf{H}_{\mathbf{A}}$ & $2.66(2.92)$ & $3.11(3.12)$ & $2.94(3.08)$ & $2.98(3.06)$ & $4.02(2.87)$ & $1.24(1.19)$ & $1.02(1.02)$ \\
$\mathbf{O}_{\mathbf{B}}-\mathbf{S}_{\mathbf{A}}$ & $3.85(3.80)$ & $4.68(4.29)$ & $5.11(5.19)$ & $5.03(5.42)$ & $5.06(3.44)$ & $2.69(2.47)$ & $1.70(1.66)$ \\
\hline
\end{tabular}

In TS1, the nucleophile is located at $2.02 \AA$ from carbon of substrate, while the bond with the sulfur has lengthened to the value of $2.58 \AA$ respect to initial $1.71 \AA$ in the ES complex. The more negative charge that resulted on the nitrile nitrogen after the nucleophile attack strengthens its bond with the metal ion (1.89 $\AA$ versus $1.99 \AA$ in the ES). All rearrangements lead to the formation of a five-termed structure, in analogy to the observation raised from crystallographic studies on the $\mathrm{Co}^{3+}-\mathrm{NHase}$-inhibitor (PBA) [117]. The value of the imaginary frequency at $262 i \mathrm{~cm}^{-1}$ well correlates with the stretching of the $\mathrm{S}-\mathrm{OH}$ and $\mathrm{O}-\mathrm{H}-\mathrm{N}$ bonds. The TS1 lies at $19.6 \mathrm{kcal} / \mathrm{mol}$ above the reagents, thus, the barrier that must be considered is $25.6 \mathrm{kcal} / \mathrm{mol}$. The only possible comparison can be made with some previous theoretical results on $\mathrm{Fe}^{3+}-\mathrm{NHase}$ in which barriers span from 20.2 to $22.7 \mathrm{kcal} / \mathrm{mol}$, according to the explored mechanism. At the experimental level, concerning always the iron-containing enzyme, even lower values are suggested.

In the next INT1 intermediate, presenting energy of $4.9 \mathrm{kcal} / \mathrm{mol}$ with respect to $\mathrm{E}+\mathrm{S}$, the iminol moiety distance from metal ion does not change. The oxygen atom of the nucleophile group presented a distance of $3.17 \AA$ from the sulfur of the $\alpha$ Cys 113 and forms a single bond with carbon, as highlighted by length of $1.41 \AA$.

It is interesting to point out that in INT1, the $-\mathrm{OH}$ of the $\alpha$ Ser112 is at $1.98 \AA$, resulting in closer distance to the substrate's nitrogen, with respect to the ES complex (2.44 $\AA$ ). The H-bond of serine with the substrate during the nucleophile attack is useful for its next role in the process.

The TS2, in good agreement with the available experimental results, [111] describes a concerted transfer of protons, which occurs at the imaginary frequency of $1841 i \mathrm{~cm}^{-1}$. These transfers involve the $\alpha \mathrm{Cys} 113-\mathrm{OH}$ and the nitrogen atom of benzonitrile, mediated by the water molecules network. $\mathrm{w} 1$, next in proximity of the iminol's $-\mathrm{OH}$ accepts a proton $(1.13 \AA)$, donating the one to the w2 $(1.23 \AA)$. This, in turn, donates a proton to the $-\mathrm{OH}$ moiety of the $\alpha$ Ser112. The $\alpha$ Ser112, finally, delivers its proton to the nitrogen atom of the substrate. The TS2 lies at $19.7 \mathrm{kcal} / \mathrm{mol}$ above $\mathrm{E}+\mathrm{S}$. In the INT2 are depicted all the results of transfers previously described. Despite the formation of benzamide, its coordination to the metal is evidenced by the distance of $1.90 \AA$. The INT2 lies at $19.3 \mathrm{kcal} / \mathrm{mol}$ below the reactants, presenting an important thermodynamic stabilization of the complex. At this step of the mechanism, the process of hydration could be considered finished and from INT2 the theoretical investigation concerning the product release mechanism is necessary to restore the enzymatic cycle. Only one of the two explored possibility proved fruitful [118]. It consists in a nucleophile attack by a water molecule on $\alpha \mathrm{Cys} 113$ and its sulfur atom, which transforms the imidate in the corresponding amide. In the transition state (TS3), the water molecule that in the INT2 presents a distance of $2.55 \AA$ from the sulfur of $\alpha \mathrm{Cys} 113$ (4.48 $\AA$ in ES), acting as acid toward the $-\mathrm{NH}$ group. Its proton, bridging the 
oxygen and the nitrogen $(\mathrm{Ow}-\mathrm{H}$ and $\mathrm{H}-\mathrm{NH}$ distances are 1.32 and $1.22 \AA$, respectively), establishes a further hydrogen bond interaction with the nearby water molecule $(1.58 \AA)$. The obtained value for the imaginary frequency was of $1311 i \mathrm{~cm}^{-1}$, clearly referring to the stretching of the $\mathrm{O}-\mathrm{H}$ bond. The obtained barrier presented an energy of $26.3 \mathrm{kcal} / \mathrm{mol}$. In the final EP complex, the benzamide lies at $3.41 \AA$ from the metal center ready to move away permanently. The EP complex $(7.2 \mathrm{kcal} / \mathrm{mol}$ below the $\mathrm{E}+\mathrm{S}$ ) is stabilized by hydrogen bonds which water molecule establishes with both the $\beta$ Arg52 $(2.43 \AA)$ and the product $(1.81 \AA)$.

The conversion of EP into E + P occurs easily as it can be argued by structural aspects of the EP. Our calculation of the energy as a function of the shortening of the water-metal bond demonstrates its tendency to become increasingly negative, as the distance decreases. Hence, barrierless release of the product is observed. The water molecule, replacing the product, coordinated to the cobalt ion $(2.25 \AA)$. The product $(\mathrm{P})$, far from the metal coordination sphere $(4.75 \AA)$, is held in the catalytic pocket through interactions with the Leu 48 and Tyr68 residues. The relative energy values of $\mathrm{E}+\mathrm{P}$ is $-14.9 \mathrm{kcal} / \mathrm{mol}$.

Theoretical and experimental works were devoted to the study of the $\mathrm{Fe}^{3+}$-type nitrile hydratases [111,122,124,129-133]. In particular, Yamanaka et al. [128] in their X-ray crystallographic investigation proposed that the pivalonitrile substrate suffers the nucleophilic attack by the atom of $\alpha$ Cys114-SOH - residue. The step is followed by a further nucleophilic attack to the $\mathrm{S}(\mathrm{SO}-)$ atom by the $\beta$ Arg56, activated by water molecule, before releasing the amide and regenerating $\alpha$ Cys114-SO- [133] . This last study inspired our investigation in which the role played by the two water molecules $\mathrm{w} 1$ and w2 has been described.

As for the cobalt-containing enzyme, preliminary simulations on the ES of $\mathrm{Fe}^{3+}$-NHase were performed to confirm the lowest-energy spin state that resulted $S=\frac{1}{2}$, as suggested by experimental evidence [123].

The coordination of substrate to the $\mathrm{Fe}^{3+}$ cation occurs after the displacement of axial water molecule, as a result of a $\sigma$ donation to the metal, evidenced from our NBO analysis, nitrile nitrogen becomes less negative by about +0.19 |e| with respect to that of the free substrate. Then, the electron attraction occurring from the adjacent carbon makes it more electrophile. In the ES complex, w1 lies at $4.36 \AA$ from the metal ion, and the nucleophile agent $(\mathrm{S}-\mathrm{OH})$ lies farther with respect to the $\mathrm{Co}^{3+}$-type enzyme from the nitrile group ( $3.95 \AA$ vs. $3.53 \AA$ ). The TS1, describing the nucleophilic attack of cysteine-sulfenic acid on the substrate requires $16.2 \mathrm{kcal} / \mathrm{mol} 20 \mathrm{kcal} / \mathrm{mol}$ less than the uncatalyzed reaction presenting $35.6 \mathrm{kcal} / \mathrm{mol}$ at B3LYP level of theory [132].

The TS1 exhibits a cyclic structure with the elongated S- OH bond (2.89 $\mathrm{A})$ and the forming $\mathrm{C}-\mathrm{OH}$ $(1.79 \AA)$, with an angle between the carbon atom of the pivaloyl group, the $\mathrm{C}$ and $\mathrm{N}$ atoms of the nitrile group of $138^{\circ}$. In addition, these atoms lie in the same plane as the sulfenic (S-OH) group. The $\beta$ Arg56 residue implicated in a hydrogen bond with its $\mathrm{OH}$ moiety assists the step regarding the reorganization of the sulfenic group. This role of the $\beta$ Arg56 that assists this step was never investigated [133-137].

Various arguments can be used to explain the different energetic behaviors that resulted from the two $\mathrm{Co}^{3+}$ - and $\mathrm{Fe}^{3+}$-NHases.

Among these, the different ionic radius $\left(\mathrm{Co}^{3+}=53 \mathrm{pm}, \mathrm{Fe}^{3+}=55 \mathrm{pm}\right)$ and the length of the $\mathrm{C}-\mathrm{OH}$ bond (2.01 $\AA$ and $1.79 \AA$, in $\mathrm{Co}^{3+}-\mathrm{NH}$ ase and $\mathrm{Fe}^{3+}-\mathrm{NHase}$, respectively) in TS1 justifies the observed trend. In addition, the bond order values (0.24 and 0.30) deriving from the atom-atom overlap weighted NAO analysis support an easier nucleophilic attack in the $\mathrm{Fe}^{3+}-\mathrm{NHase}$-catalyzed reaction. The molecular orbital (MO) energy diagram of ES complex of two $\mathrm{Co}^{3+}$ - and $\mathrm{Fe}^{3+}$-NHases in comparison with the related apoform (E) is depicted in Figure 7 and offers a further explanation of this different behavior.

A better overlap between the HOMO $\beta$ of apo-enzyme and the substrate's HOMO lowers the energies of frontier orbitals (HOMO $\beta$ and LUMO $\beta$ ) of the ES complex more in $\mathrm{Fe}^{3+}-\mathrm{NH}$ ase than in $\mathrm{Co}^{3+}-\mathrm{NH}$ ase. 


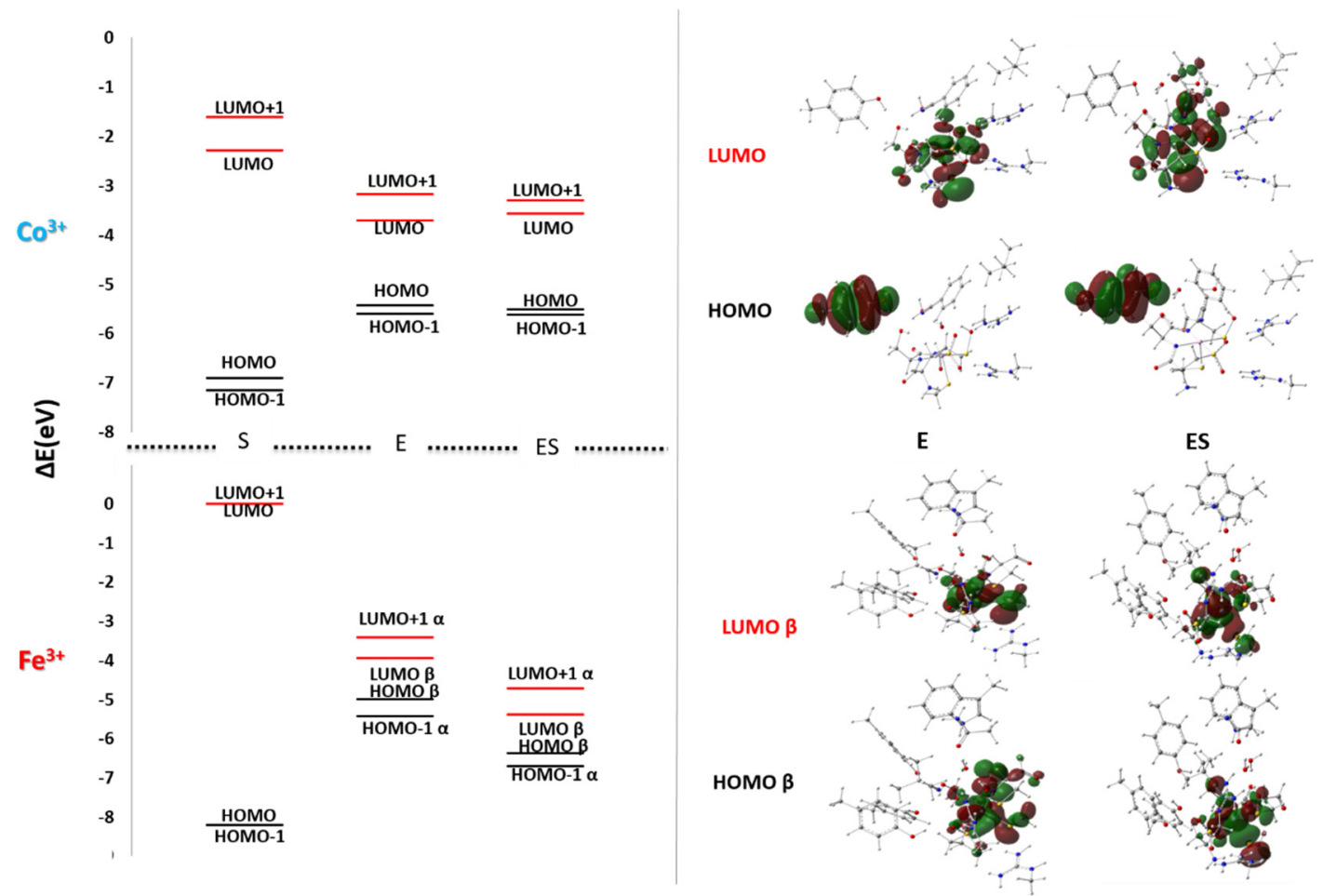

Figure 7. On the left, the energy displacement of frontier molecular orbitals of nitriles (S), apo-enzymes (E), and enzyme-substrate complexes (ES), with their relative representation, on the right.

In the INT1 of $\mathrm{Fe}^{3+}$-NHase, $\alpha$ Cys114 OH-S distance (3.24 $\AA$ ) gets longer and the $\mathrm{C}-\mathrm{OH}$ bond resulted (1.36 $\AA$ ). The process continues with a concerted proton transfer (TS2), analogously to the $\mathrm{Co}^{3+}-\mathrm{NH}$ ase, mediated by the water molecules, located between the $-\mathrm{OH}$ groups of the iminol and of the serine $(1.30 \AA)$. $w 1$ receives the proton $(1.37 \AA)$ from the $\mathrm{C}-\mathrm{OH}$ moiety of the substrate, donating the other one to w2 (1.39 $\AA$ ), which through the Ser-OH delivers it to the nitrogen atom, forming amidate. TS2 lies at $14.2 \mathrm{kcal} / \mathrm{mol}$ above reactants.

The next stationary point on the PES is INT2 that lies at $24.1 \mathrm{kcal} / \mathrm{mol}$ above the ES.

Similarly to what was found in the $\mathrm{Co}^{3+}-\mathrm{NH}$ ase, in TS3 of $\mathrm{Fe}^{3+}$-NHase the water molecule mediates the formation of the product and of the $\mathrm{S}-\mathrm{O}$ bond of $\alpha \mathrm{Cys} 114$. The Arg56 residue anchors $\mathrm{w} 1$ and $\mathrm{w} 2$ near the reaction site via a hydrogen bond network. The simultaneous attack of $\mathrm{w} 1 \mathrm{on}$ the sulfur atom of $\alpha$ Cys114 (2.47 $\AA$ ) and the donation of the proton to the $-\mathrm{NH}$ group $(1.35 \AA)$ of the deprotonated amide coordinated to the iron ion $(2.10 \AA)$, as evidence by visualization of imaginary frequency. The energy of the stationary points is about $8 \mathrm{kcal} / \mathrm{mol}$ higher than $\mathrm{Co}^{3+}$-NHase. This result is in agreement with the previous FTIR analyses of NHase in which, following the catalysis in presence of $\mathrm{H}_{2}{ }^{18} \mathrm{O}$, Yamanaka et al. noted the marked oxygen atom on the $\alpha$ Cys114 residue [130].

In the EP species lying at about $24 \mathrm{kcal} / \mathrm{mol}$ below the reactants, the formation of amide is already completed and the distance of $\mathrm{Fe}^{3+}-\mathrm{N}_{\mathrm{A}}$ is $3.99 \AA$, which indicates that the product is practically released. $w 2, \beta$ Arg56, $\alpha$ Cys114, and $\alpha \mathrm{Gln} 90$ residues are all involved in a network of stabilizing hydrogen interactions.

The formation of the EP complex represents the biggest obstacle in the reaction for both enzymes with activation barriers of 26.3 and $24.6 \mathrm{kcal} / \mathrm{mol}$ for $\mathrm{Co}^{3+}$ - and $\mathrm{Fe}^{3+}$ - NHase, respectively.

For cobalt enzyme, this result does not affect the conclusions concerning the rate-limiting step of the process because the first nucleophile attack requires almost the same amount of energy than the EP formation, as evidenced by a difference of about $1 \mathrm{kcal} / \mathrm{mol}$. In the case of iron, the energy barriers presented different values. However, we have to emphasize that the formation of the EP complex represents the phase of restoring of the catalyst and that the amide has formed in the INT2. Focusing 
on the formation of the amide, we could then say that the nucleophilic attack (TS1) on the nitrile carbon atom is the rate-limiting step of both processes. In the absence of incontrovertible experimental data, we too cannot provide definitive indications. The reassuring thing is that the barriers we propose are compatible with a catalytic process.

\section{5. $\mathrm{Co}^{2+}-\mathrm{Co}^{2+}$ and $\mathrm{Mn}^{2+}-\mathrm{Mn}^{2+}$ Arginase}

The arginase (EC 3.5.3.1) is a hydrolase manganese-containing enzyme that converts arginine to urea and ornithine (depicted in Scheme 5), an important step in the urea cycle and regulator of several important pathways, including nitric oxide, proline, and polyamine biosynthesis [138,139].<smiles>N=C(N)NCCCC([NH3+])C(=O)O</smiles>

Argininine<smiles></smiles>

Urea

Ornithine

Scheme 5. The arginine hydrolysis reaction.

Arginases require a divalent cation activator to maintain their stable native state. Although the physiological activator is $\mathrm{Mn}^{2+}$, the mammalian enzyme can be activated also by, $\mathrm{Co}^{2+}, \mathrm{Ni}^{2+}, \mathrm{Fe}^{2+}$, and $\mathrm{Cd}^{2+}$ ions [140,141].

In 2010, by substitution of the $\mathrm{Mn}^{2+}-\mathrm{Mn}^{2+}$ cluster with $\mathrm{Co}^{2+}-\mathrm{Co}^{2+}$ in the active site, an enzyme with greater activity has been obtained [142]. In an attempt to rationalize the lower $\mathrm{K}_{\mathrm{M}}$ value of L-Arg and the lower $\mathrm{K}_{\mathrm{i}}$ value caused by the replacement of L-Orn, Stone et al. proposed a different catalytic mechanism for $\mathrm{Co}^{2+}$-arginase compared with the $\mathrm{Mn}^{2+}$ containing enzyme [142].

However, more recently, the conclusions drawn by this previous work [141] were drastically changed by subsequent $X$-ray diffractometric study [143]. Since no significant structural differences were found for the two $\left(\mathrm{Mn}^{2+}-\mathrm{Mn}^{2+}\right)$ and $\left(\mathrm{Co}^{2+}-\mathrm{Co}^{2+}\right)$-arginases, our DFT quantum-chemical study on both enzymes can provide atomistic details helpful for better clarifying their catalytic activity. The reaction mechanism followed by the two enzymes is reported in the Scheme 6 . The best characterized arginase is that obtained from rat liver $[144,145]$ which is a homotrimeric protein.

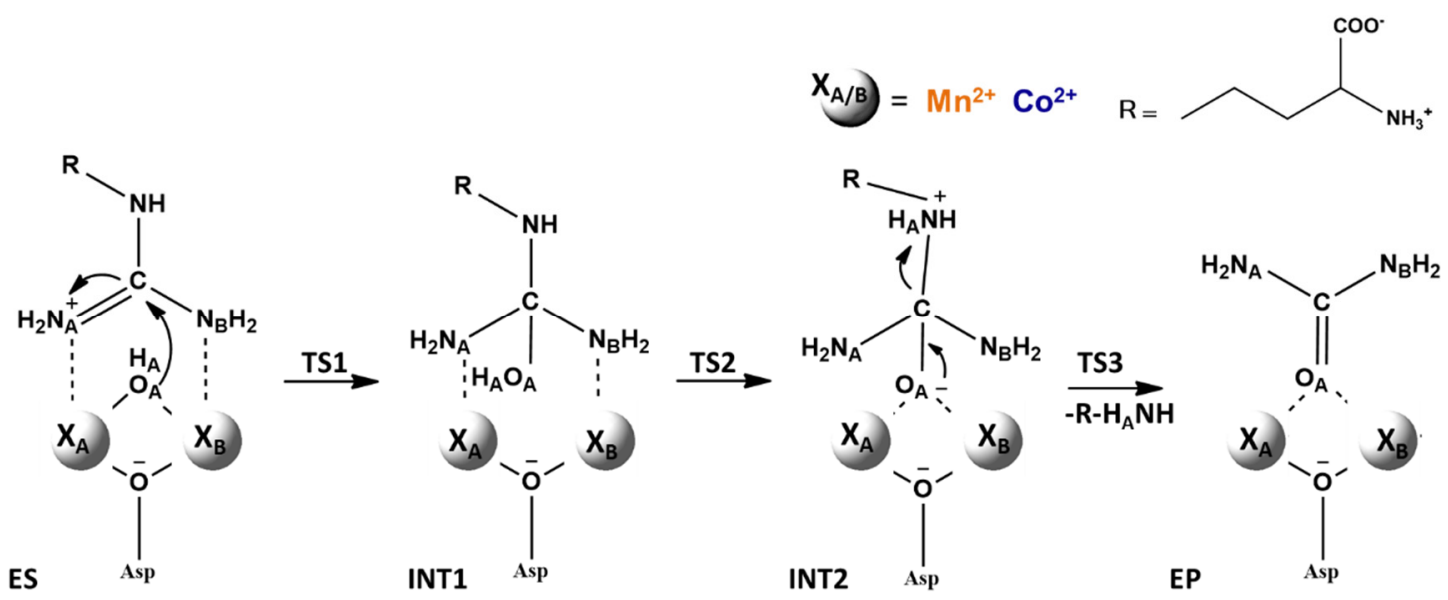

Scheme 6. Catalytic mechanism proposed for the two arginases $\left(\mathrm{X}_{\mathrm{A}}\right.$ and $\mathrm{X}_{\mathrm{B}}$ where $\mathrm{X}=\mathrm{Mn}^{2+}$ or $\left.\mathrm{Co}^{2+}\right)$.

The active site of enzymes obtained from PDB code 1D3V [146] and applying the cluster model approach is depicted in Figure 8 for both $\mathrm{Mn}^{2+}$ and $\mathrm{Co}^{2+}$ enzymes because the structures previously deposited in the protein data bank showed that $\mathrm{Co}^{2+}$ substitution does not generate any important structural changes in the active site of human arginase [143]. 


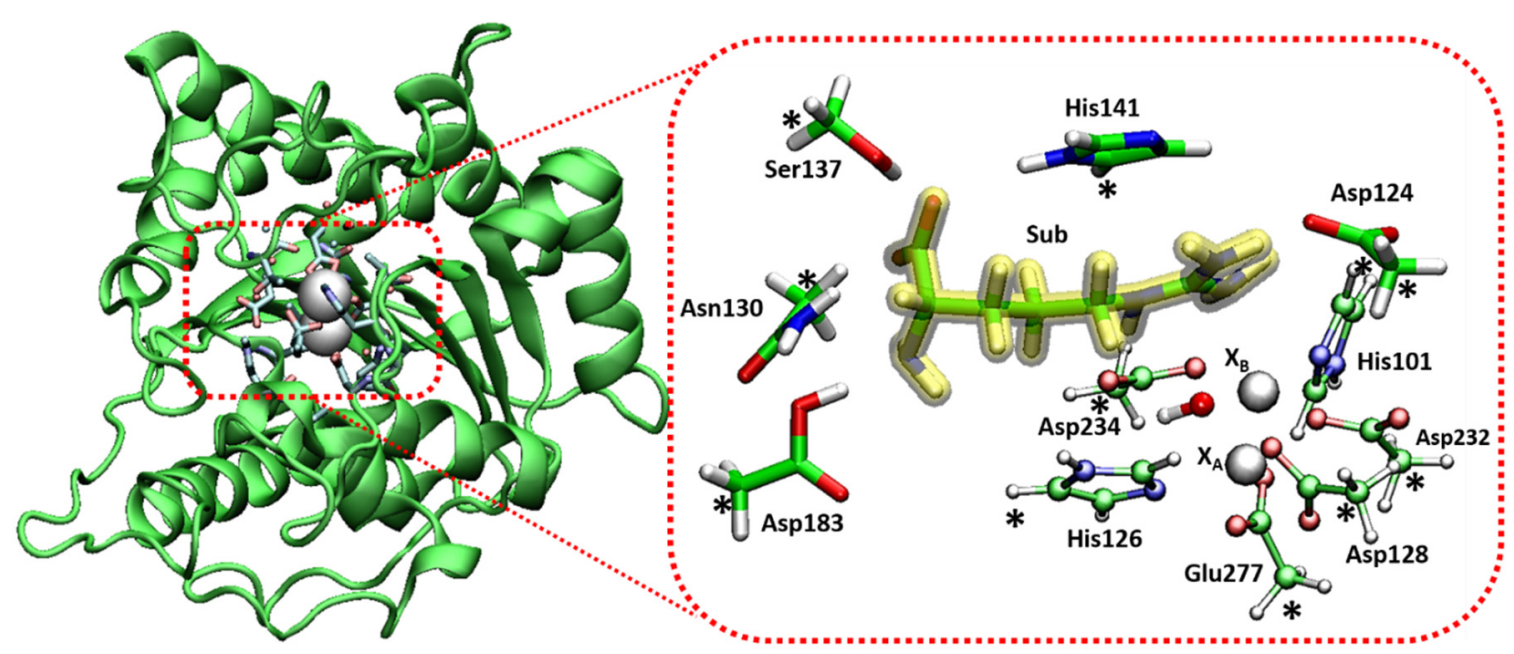

Figure 8. $\mathrm{QM}$ cluster model of $\mathrm{X}_{\mathrm{A}}-\mathrm{X}_{\mathrm{B}}$ arginase $\left(\mathrm{X}_{\mathrm{A}} / \mathrm{X}_{\mathrm{B}}=\mathrm{Co}^{2+}, \mathrm{Mn}^{2+}\right)$ active site. Stars indicate the frozen atoms during the optimizations.

In each subunit, a pair of spin-coupled divalent ions $\left(X_{A}\right.$ and $X_{B}$ where $X=\mathrm{Mn}^{2+}$ or $\left.\mathrm{Co}^{2+}\right)$ is present. His101 and Asp128 residues are coordinated to $X_{A}$ center, while His126 and Asp234 are coordinated to $X_{B}$ one. The residues Asp124, Asp232, and a water molecule/hydroxyl group involved in a hydrogen bond with Asp128 [147] act as bridging ligands for the two metal ions.

As in the $2.4 \AA$ crystal structure of Bacillus caldovelox arginase complexed [148], the substrate arginine appears symmetrically coordinated to the two metal ions, and its carbonyl carbon atom lies at about $2.74 \AA$ Á from the bridging ion/water $\left(\mathrm{OH} / \mathrm{H}_{2} \mathrm{O}\right)$. The bi-nuclear cluster $\mathrm{Mn}^{2+}-\mathrm{Mn}^{2+}$ strongly enhances the formation of $\mathrm{OH}^{-}$agent, as evidenced by turnover measurements determining a pKa for the bridging ligand of 7.9, sensibly different to that available for a single $\mathrm{Mn}^{2+}$ [149]. Asp128 residue interacts strongly with the hydroxyl $\left(\mathrm{OH} / \mathrm{H}_{2} \mathrm{O}\right)$. The guanidine moiety is involved in hydrogen bond with Glu277 and His141.

Preliminary calculations on the ES complex for cobalt enzyme were performed with the aim of establishing the most stable spin multiplicity of the system. Different values of spin multiplicity $(2 S+1=3,5,7$, and 9$)$ were considered but by far the lowest energy was obtained with a value equal to 7 .

The hydrolysis reaction starts with the binding of arginine to the metal ions through the $-\mathrm{NH}_{2}$ groups. The substrate is thus in optimal position to undergo the nucleophilic attack by the bridging $\mathrm{OH}$ group, leading to a tetrahedral intermediate.

A comparison between the structure of ES complex of $\mathrm{Mn}^{2+}$ and $\mathrm{Co}^{2+}$ containing arginase shows that the nitrogen atoms of the substrate are closer to $\mathrm{Co}^{2+} \mathrm{A}(2.44 \AA)$ than to $\mathrm{Mn}^{2+} \mathrm{A}(2.56 \AA)$.

A previous experimental investigation suggested that this should derive from different electrostatic distributions in the active site [143]. Our NBO analysis did not evidence any significant difference in the net charges values on the metal centers, on the $\mathrm{O}$ atom of the hydroxyl group, and on the carbonyl $\mathrm{C}$ atom of the substrate in the two cases. A possible explanation resides in the relative affinity of the two metallo-enzymes. These were obtained via single-point energy calculations on optimized $\mathrm{Co}^{2+}-$ and $\mathrm{Mn}^{2+}$-containing ESs, according to the Scheme 7.

$$
\begin{aligned}
& E_{X A / X B}+S \rightarrow E_{X A / X B} S \quad X_{A} / \mathrm{X}_{B}=\mathrm{Co}^{2+}, \mathrm{Mn}^{2+} \\
& \Delta E_{\text {affinity }}=E\left(E_{X A / X B} S\right)-E\left(E_{X A / X B}\right)-E(S) \\
& \Delta \Delta E_{\text {affinity }}=\Delta E_{\text {affinity }}\left(\mathrm{Mn}^{2+}-\mathrm{Mn}^{2+}\right)-\Delta E_{\text {affinity }}\left(\mathrm{CO}^{2+}-\mathrm{CO}^{2+}\right)
\end{aligned}
$$

Scheme 7. Illustration of the procedure adopted in the estimation of relative affinities. 
In the case of $\mathrm{Mn}^{2+}-\mathrm{Mn}^{2+}$-containing enzyme, a relative affinity $\Delta \Delta \mathrm{E}_{\text {affinity }}$ of $+2.9 \mathrm{kcal} / \mathrm{mol}$ was calculated with respect to the $\mathrm{Co}^{2+}-\mathrm{Co}^{2+}$ arginase. This behavior is in agreement with the experimentally observed $\mathrm{K}_{\mathrm{M}}$, lower in the case of the Co with respect to the $\mathrm{Mn}$. This indicates that the stronger interaction established by the $\mathrm{Co}^{2+}-\mathrm{Co}^{2+}$ arginase can favors the closeness of the substrate to the metal centers.

The formation of the ES complex is followed by the nucleophilic addition by the bridging $-\mathrm{OH}$ to the iminium $C$ ion of arginase as confirmed by the imaginary frequency of $249 i \mathrm{~cm}^{-1}$ and $259 i \mathrm{~cm}^{-1}$ associated with the $\mathrm{HO}-\mathrm{C}$ stretching mode for $\mathrm{Mn}^{2+}$ - and $\mathrm{Co}^{2+}$ - enzyme, respectively.

From the values of $\mathrm{HO}-\mathrm{C}$ bond (1.75 and $1.80 \AA$ in $\mathrm{Mn}^{2+}$ - and $\mathrm{Co}^{2+}$ - enzyme, respectively, see Table 4) we can see that it is already pretty much formed. NBO analysis indicates for $\mathrm{HO}-\mathrm{C}$ bond a $\sigma$ nature, substantially an overlap of $\mathrm{p}$ orbitals of $\mathrm{O}$ and $\mathrm{C}$ atoms.

Table 4. Geometrical parameters obtained for the isolated stationary point along the reaction mechanism of $\mathrm{Co}^{2+}-\mathrm{Co}^{2+}$ arginase and $\mathrm{Mn}^{2+}-\mathrm{Mn}^{2+}$ arginase (in parenthesis) $[150,151]$. All values are in $\AA$.

\begin{tabular}{cccccccc}
\hline Distances & ES & TS1 & INT1 & TS2 & INT2 & TS3 & EP \\
\hline $\mathbf{X}_{\mathbf{A}}-\mathbf{O}_{\mathbf{A}}$ & $2.02(2.07)$ & $2.17(2.28)$ & $2.89(2.69)$ & $2.41(2.26)$ & $2.19(2.29)$ & $2.54(2.35)$ & $3.20(2.54)$ \\
$\mathbf{X}_{\mathbf{B}}-\mathbf{O}_{\mathbf{A}}$ & $1.98(2.07)$ & $2.12(2.21)$ & $2.25(2.16)$ & $2.21(2.32)$ & $2.13(2.16)$ & $2.05(2.18)$ & $1.98(2.14)$ \\
$\mathbf{O}_{\mathbf{A}}-\mathbf{C}$ & $2.79(2.83)$ & $1.80(1.75)$ & $1.44(1.48)$ & $1.41(1.43)$ & $1.34(1.34)$ & $1.30(1.30)$ & $1.27(1.28)$ \\
$\mathbf{N}-\mathbf{H}_{\mathbf{A}}$ & $2.83(2.81)$ & $2.47(2.43)$ & $2.53(2.64)$ & $2.60(2.47)$ & $1.06(1.06)$ & $1.03(1.04)$ & $1.02(1.02)$ \\
$\mathbf{N}-\mathbf{C}$ & $1.36(1.34)$ & $1.40(1.40)$ & $1.45(1.45)$ & $1.45(1.45)$ & $1.59(1.61)$ & $1.96(1.96)$ & $3.42(3.31)$ \\
\hline
\end{tabular}

The charge distribution on all atoms involved in the nucleophilic attack is analogous in the two $\mathrm{Mn}^{2+}$ - and $\mathrm{Co}^{2+}$ - enzyme (see Figure 9); the only difference that occur on the nitrogen atoms of substrate and iminium $C$ ion. These, along with the ionic radii reflect on the values of $\mathrm{Mn}_{\mathrm{A}}-\mathrm{N}_{\mathrm{A}}(2.33 \AA)$ and $\mathrm{Co}_{\mathrm{A}}-\mathrm{N}_{\mathrm{A}}(2.20 \AA)$ distances, confirm again that the substrate is better anchored in the cobalt-containing enzyme. As it can be seen from Figure 10, for both enzymes TS1 lies at about $16.0 \mathrm{kcal} / \mathrm{mol}$ and represents the rate-limiting steps of the reaction. The nucleophilic addition is followed by the formation of the tetrahedral intermediate INT1 which we found at $13.5\left(\mathrm{Mn}^{2+}\right)$ and $13.7\left(\mathrm{Co}^{2+}\right) \mathrm{kcal} / \mathrm{mol}$ above ES.

The HO-C bond assumes the value of $1.44 \AA$ in both cases and the $\mathrm{OH}$ - group remains weakly anchored to only one of the two centers of the bimetallic cluster.

In TS2, a proton transfer from the -OH to the Asp128 must take place for proton delivery from this residue to the $\mathrm{N}$ atom of the substrate. In the case of $\mathrm{Mn}^{2+}$-enzyme, the event requires about $2.0 \mathrm{kcal} / \mathrm{mol}$. Distances for the $\mathrm{O}_{\mathrm{Asp} 128}-\mathrm{H}$ and $\mathrm{H}-\mathrm{O}$ bonds are 1.18 and $1.26 \AA$ and imaginary frequency falls at $535 \mathrm{icm}^{-1}$. For $\mathrm{Co}^{3+}$-enzyme the $\mathrm{O}_{\mathrm{Asp} 128}-\mathrm{H}$ and $\mathrm{H}-\mathrm{O}$ bonds are $1.51 \AA$ and $1.03 \AA$ and imaginary frequency is $148 \mathrm{icm} \mathrm{cm}^{-1}$.

The graph of Figure 10 shows an anomalous behavior for $\mathrm{Co}^{2+}$-enzyme. In fact, the TS2 lies below the intermediate INT1. This tendency has been previously noted in other enzymes for the hydrogen-transfer process and depends on the functional used for computations, namely B3LYP. 


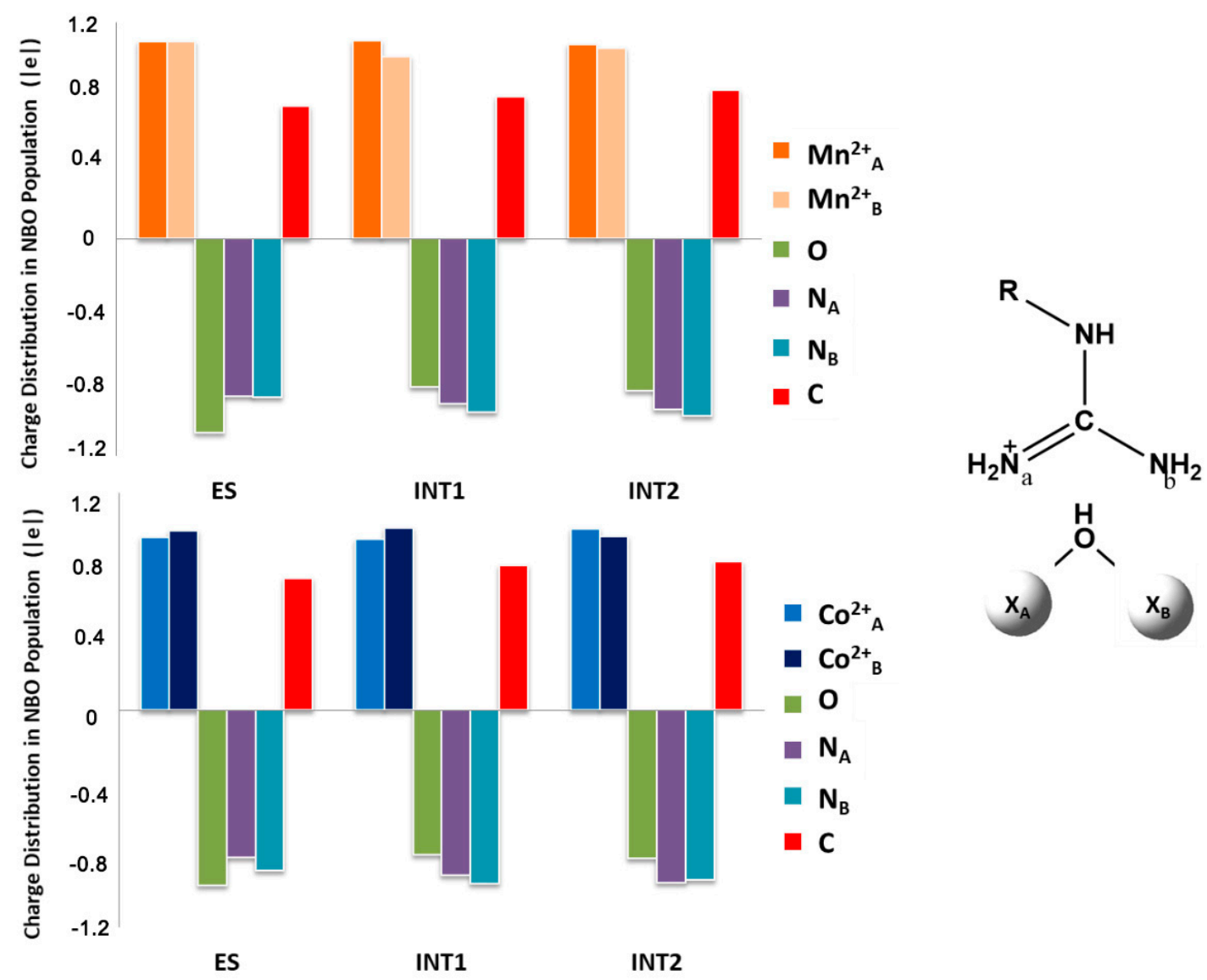

Figure 9. Charge distributions in significant stationary points on the energy profiles of $\mathrm{Co}^{2+}-\mathrm{Co}^{2+}$ and $\mathrm{Mn}^{2+}-\mathrm{Mn}^{2+}$ arginase enzymes.

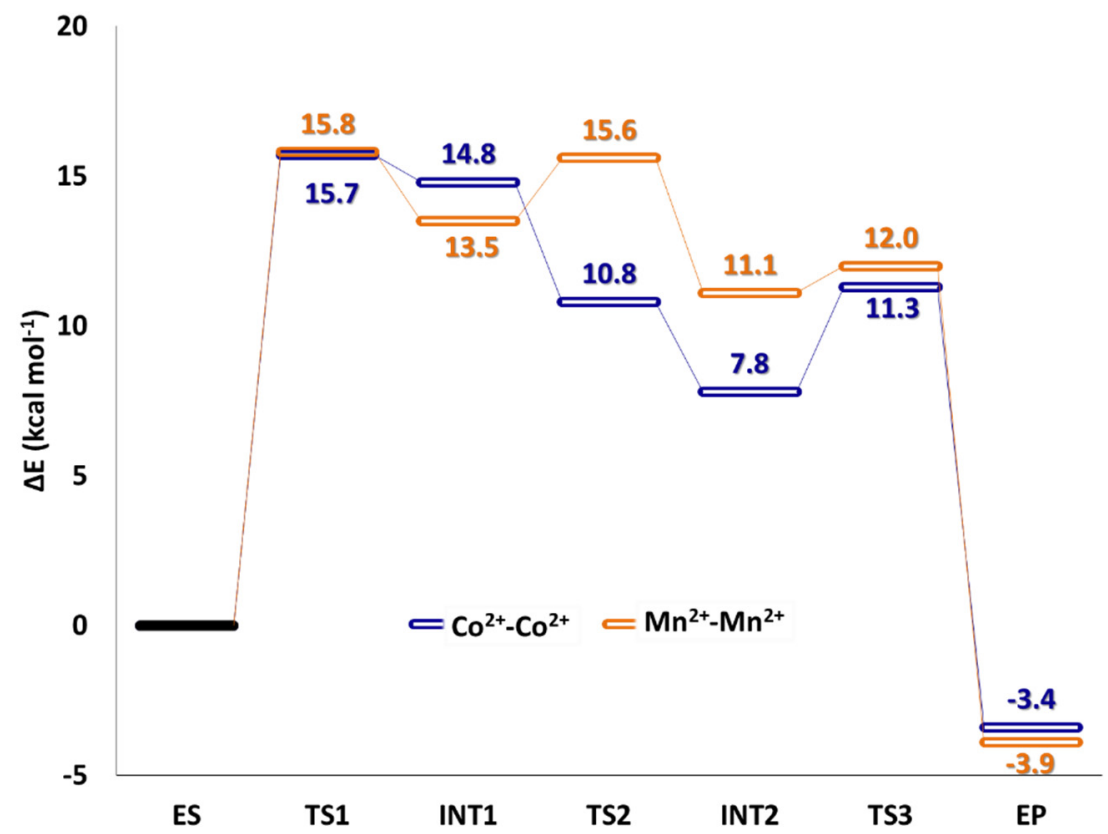

Figure 10. $\operatorname{PCM}(\varepsilon=4) / B 3 L Y P / 6-311+G(d, p) \mid S D D$ energetic profiles of hydrolysis mechanism of $\mathrm{Co}^{2+}-\mathrm{Co}^{2+}$ and $\mathrm{Mn}^{2+}-\mathrm{Mn}^{2+}$ arginase $[150,151]$.

As discussed in the previous manuscript, this anomalous trend was fixed adopting other functionals [150]. 
However, since the step in question is not fundamental to the kinetics of the reaction, and in order to compare the data for cobalt containing enzyme with those obtained for the enzyme with manganese, we have chosen to bring back here the values obtained at B3LYP level.

The reaction proceeds with the formation of INT2. The proton of the carboxyl group of Asp128 spontaneously moves toward the nitrogen $(\mathrm{N})$ of arginine. The $\mathrm{C}-\mathrm{N}$ bond stretches from its normal value of about $1.47 \AA$ to $1.61\left(\mathrm{Mn}^{2+}\right.$-arginase $)$ and $1.60 \AA\left(\mathrm{Co}^{2+}\right.$-arginase $)$. Instead, the $\mathrm{C}-\mathrm{O}$ bond is shortened until $1.34 \AA$ in both enzymes.

INT2 is located at $11.1 \mathrm{kcal} / \mathrm{mol}$ and $7.8 \mathrm{kcal} / \mathrm{mol}$ above ES for $\mathrm{Mn}^{2}+-$ and $\mathrm{Co}^{2+}$ - arginase, respectively.

In order to achieve the final products urea and ornithine, $\mathrm{C}-\mathrm{N}$ bond must be definitively broken. The process requires always a small amount of energy (see Figure 10) in the protein environment.

The visual inspection of imaginary frequency $\left(192 i \mathrm{~cm}^{-1}\right.$ for $\mathrm{Mn}^{2+}$ and $147 i \mathrm{~cm}^{-1}$ for $\left.\mathrm{Co}^{2+}\right)$ reveals the stretching of the $\mathrm{C}-\mathrm{N}$ bond.

In the resulting enzyme-product complex EP, both hydrolysis products are still retained in the active site. Urea interacts by the carbonyl $\mathrm{O}$ atom with $\mathrm{Co}_{\mathrm{B}}(1.99 \AA)$ and by $\mathrm{N}_{\mathrm{A}}$ with $\mathrm{Co}_{\mathrm{A}}(2.29 \AA)$. In the case of $\mathrm{Mn}^{2+}$-arginase these distances are only longer. Ornithine establishes hydrogen bonds with the neighboring residues (Asp128 and His141) and interacts with the Ser137, Asn130, and Asp183 residues through its $\alpha$-amino and $\alpha$ carboxylate groups. In a very similar way to what occurred in $\mathrm{Mn}^{2+}$-arginase and in the corresponding experimental structures [143,151], ornithine side chain is extended into the active site adopting a trans conformation. This means that the $\mathrm{N} \varepsilon$ atom of arginine cannot establish contacts with metal ions and so cannot assume the orientation suggested by Stone et al. [152].

The comparison between the $\mathrm{Co}^{2+}$ - and $\mathrm{Mn}^{2+}$-containing arginase evidences that the barriers for the rate-determining step are practically identical, in agreement with the measured experimental $k_{\text {cat }}$ values in both enzymes $[152,153]$. The differences in $\mathrm{K}_{\mathrm{M}}$ can be explained by the computed binding energies in the Michaelis complex (ES).

\section{The Relevance of Metal Ions in the Three Selected Enzymes}

The three cases showed the effect carried by the presence of different metal ions in the same catalytic task. The mechanistic insights presented above, in particular, highlighted the main role of the metal center in triggering the reaction in the early stage, usually the TS1 of catalytic mechanism. Except for the arginase, the initial step of the catalytic mechanism does not affect the kinetic of the reaction and, presumably, this evidence can be attributed to the direct participation of metal in the step of the reaction, due to different effects that will be highlighted in this paragraph.

The number of examples presented here are remarkably lower with respect to the huge number of metalloproteins that are nowadays known, and for this reason, it is not possible to generalize about the effect of metal in enzymes. On the other hand, the presentation of selected cases may help the extrapolation of the catalytic behavior of metal for the discussed enzymes and the "pure" effect dictated by the presence of that metal. It is worth noting, indeed, that for the studied cases no significant variations, in particular in terms of model's charges and oxidation numbers of the metals and reaction coordinate characterizing the mechanism, have been encountered and this made the comparison between similar metals more reliable. In Figure 11 are illustrated the TS1s in which the metals were directly involved in the reaction of the three selected cases.

In the case of Lns-dependent $\mathrm{MDH}$, the role of the $\mathrm{Ce}^{3+}$ and $\mathrm{Eu}^{3+}$ in the first phase of the reaction was to facilitate the attack of the substrate's oxygen (TS1, see Figure 11A), enhancing its nucleophilicity, to the C5 of PQQ. In addition, the LUMO of PQQ cofactor was more stabilized in the case of Ce, with respect to the $\mathrm{Eu},[100,106]$ thus explaining the energy difference of about $4 \mathrm{kcal} / \mathrm{mol}$ calculated for the addition step (see Figure 4). The values obtained for the two Lns were substantially lower than the rate-determining step (the elimination), in which the presence of metal ions mainly ensure the stability of the architecture of the active site. Anyway, a recent work highlighted as the presence of 
different elements belonging to the lanthanides, additionally influences the steps in which the metal is not involved in reaction, due to the $f$-contraction effect that is a peculiarity of the series [105].
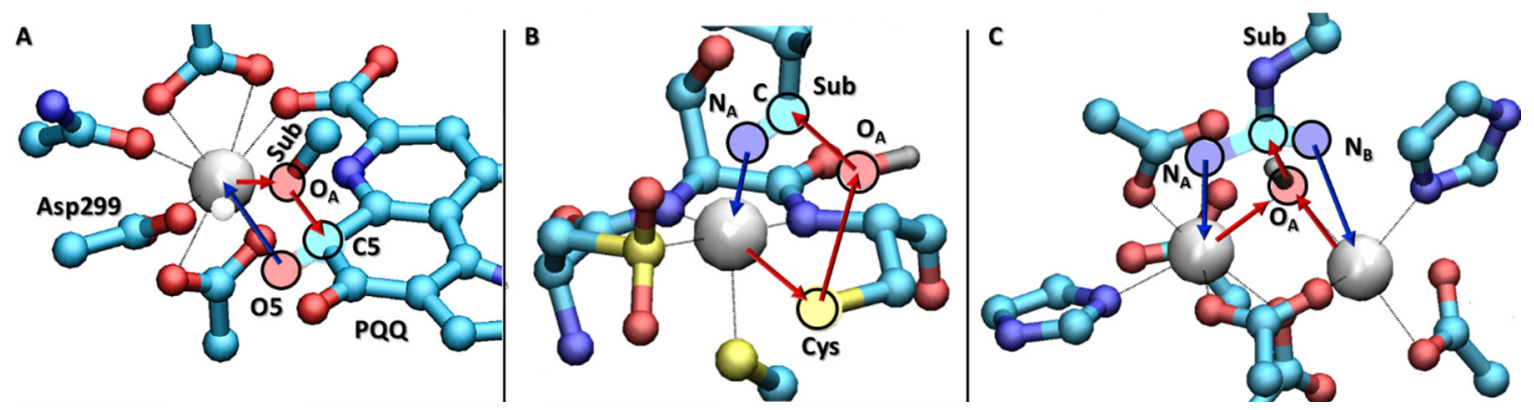

Figure 11. Optimized structures of TS1 isolated along potential energy surfaces of $(\mathbf{A}) \mathrm{Ce}^{3+}-$ and $\mathrm{Eu}^{3+}-\mathrm{MDH},(\mathbf{B}) \mathrm{Co}^{3+}-$ and $\mathrm{Fe}^{3+}-\mathrm{NH}$ ase, and (C) $\mathrm{Mn}^{2+}-\mathrm{Mn}^{2+}$ and $\mathrm{Co}^{2+}-\mathrm{Co}^{2+}$ arginase.

A slightly different behavior was presented for the $\mathrm{Fe}^{3+}$ and $\mathrm{Co}^{3+}$-dependent NHase. In this case, the metal ion is principally involved in the orientation of the substrate that undergoes attack of mutated Cys residue (Figure 11B). In analogy to the MDH, the initial phase does not represent the limiting step, which is represented by the product release (TS3), as well-known for the NHases. By the way, in the first phase of the reaction, the metal generated a strong difference of about $8 \mathrm{kcal} / \mathrm{mol}$ between the $\mathrm{Fe}^{3+}$ - and $\mathrm{Co}^{3+}$-NHAse.

In fact, despite both cations presented a low spin configuration and the same charge, the $\mathrm{Fe}^{3+}$ presented an open shell configuration, while the $\mathrm{Co}^{3+}$ the closed one, due to the different number of valence-shell electrons. The consequence of this difference is clearly shown in the Figure 6, in which the $\mathrm{MO}$ of the $\mathrm{Fe}^{3+}$-NHase presented a more stabilized energy in both $\mathrm{E}$ and $\mathrm{ES}$ stationary points, with respect to the $\mathrm{Co}^{3+}$-NHase. In addition, in the case of $\mathrm{HOMO}_{\mathrm{ES}}$ of $\mathrm{Fe}^{3+}$-NHase the electrons resulted in proximity of the non-heme ring, including the nucleophilic agent $\mathrm{OH}^{-}$, while in the case of the $\mathrm{Co}^{3+}$-NHase mainly localized in proximity of the $\pi$ system belonging to the Tyr68, thus explaining the energy difference above mentioned. This evidence further explains the TS1 barrier for the $\mathrm{Co}^{3+}$-NHase occurring with a comparable energy to the TS3 (the release of the product).

Finally, the most similar trend between the two metalloenzymes was observed for the $\mathrm{Co}^{2+}-\mathrm{Co}^{2+}$ and $\mathrm{Mn}^{2+}-\mathrm{Mn}^{2+}$ arginase. Differently from the other two cases, the step in which the metal comes into play is not only the first but also the limiting one of the entire catalytic cycle (see Figure 10C). In this case, differently from previous systems, the presence of bi-nuclear cluster eliminates the differences between the electronic natures of the two cations, generating comparable activation barriers with a small energy difference of $0.1 \mathrm{kcal} / \mathrm{mol}$.

The bridging ligand $\mathrm{OH}^{-}$nucleophile, additionally, is strongly affected by the presence of two cations, thus favoring the addition to guanidine group of arginine, in contraposition to what was simply concluded by recent work [153]. In fact, full QM calculation demonstrated that the potential energy surface obtained in the absence of one cation presented a TS1 with a higher energy of about $13 \mathrm{kcal} / \mathrm{mol}$, despite the metal centers are not involved in the binding of the substrate [151]. In addition, the $\mathrm{OH}^{-}$species is more stabilized by the $\mathrm{Mn}^{2+}$ and $\mathrm{Co}^{2+}$ species, with respect to other common physiologically relevant ions, such as $\mathrm{Mg}^{2+}$ and $\mathrm{Ca}^{2+}$, because of the availability of $3 d$ orbitals and the lower charge density [151].

As a consequence of this different nature, the presence of two metal centers additionally can favor the correct orientation of the substrate in the active site during the subsequent steps of the reaction, because of the establishment of interaction with the $\mathrm{N}_{\mathrm{A}}$ and $\mathrm{N}_{\mathrm{B}}$ atoms of the substrate. 


\section{Conclusions}

In this review, we have reported some theoretical results that highlight the fundamental role of the metal in the active site of three metalloenzymes.

Results show as:

- The metals can play different roles that dictate the catalytic reaction mechanisms and the corresponding kinetic behaviors suggesting the principle "similar but not the same";

- The quantum mechanical-based theoretical methods can give reliable results not only in reproducing known data but mainly in elucidating the chemical processes in the fascination field of enzymology.

Author Contributions: M.P., M.E.A., N.R., M.T., and T.M. wrote the manuscript and contributed to the final version of the manuscript. All authors have read and agreed to the published version of the manuscript.

Funding: This research received no external funding.

Acknowledgments: We thank the Università degli Studi della Calabria-Dipartimento di Chimica e Tecnologie Chimiche (CTC) for the support.

Conflicts of Interest: The authors declare no conflict of interest.

\section{References}

1. Crabtree, R.H. The Organometallic Chemistry of Transition Metals, 7th ed.; Wiley: Hoboken, NJ, USA, 2014; pp. 436-468.

2. Hilvert, D. Design of Protein Catalysts. Annu. Rev. Biochem. 2013, 82, 447-470. [CrossRef] [PubMed]

3. Bertini, I.; Gray, H.B.; Stiefel, E.I.; Valentine, J.S. Biological Inorganic Chemistry. Structure and Reactivity; University Science Books: Mill Valley, CA, USA, 2007; pp. 1-31.

4. Laity, J.H.; Lee, B.M.; Wright, P.E. Zinc finger proteins: New insights into structural and functional diversity. Curr. Opin. Struct. Biol. 2001, 11,39-46. [CrossRef]

5. Rauscher, F.J., III; Morris, J.F.; Tournay, O.E.; Cook, D.M.; Curran, T. Binding of the Wilms' tumor locus zinc finger protein to the EGR-1 consensus sequence. Science 1990, 250, 1259-1262. [CrossRef]

6. Waldron, K.J.; Rutherford, J.C.; Ford, D.; Robinson, N.G. Metalloproteins and metal sensing. Nature 2009, 460, 823-830. [CrossRef] [PubMed]

7. Mikšovská, J.; Larsen, R.W. Structure-function relationships in metalloproteins. Methods Enzymol. 2003, 360, 302-329. [PubMed]

8. Zheng, Y.J.; Xia, Z.X.; Chen, Z.W.; Mathews, F.S.; Bruice, T.C. Catalytic mechanism of quinoprotein methanol dehydrogenase: A theoretical and X-ray crystallographic investigation. Proc. Natl. Acad. Sci. USA 2001, 98, 432-434. [CrossRef] [PubMed]

9. Zheng, Y.J.; Bruice, T.C. Conformation of coenzyme pyrroloquinoline quinone and role of $\mathrm{Ca}^{2+}$ in the catalytic mechanism of quinoprotein methanol dehydrogenase. Proc. Natl. Acad. Sci. USA 1997, 94, 11881-11886. [CrossRef] [PubMed]

10. Zhang, X.; Reddy, S.Y.; Bruice, T.C. Mechanism of methanol oxidation by quinoprotein methanol dehydrogenase. Proc. Natl. Acad. Sci. USA 2007, 104, 745-749. [CrossRef]

11. Chistoserdova, L. Lanthanides: New life metals? World J. Microbiol. Biotechnol. 2016, 32, 138. [CrossRef]

12. Skovran, E.; Martinez-Gomez, N.C. Just add lanthanides. Science 2015, 348, 862-863. [CrossRef]

13. Barber-Zucker, S.; Shaanan, B.; Zarivach, R. Transition metal binding selectivity in proteins and its correlation with the phylogenomic classification of the cation diffusion facilitator protein family. Sci. Rep. 2017, 7, 16381. [CrossRef] [PubMed]

14. Yamashita, M.M.; Wesson, L.; Eisenmant, G.; Eisenberg, D. Where metal ions bind in proteins (metafloprotein/protein structure/hydrophobicity contrast function). Proc. Natl. Acad. Sci. USA 1990, 87, 5648-5652. [CrossRef]

15. Dudev, T.; Lin, Y.; Dudev, M.; Lim, C. First-second shell interactions in metal binding sites in proteins: A PDB survey and DFT/CDM calculations. J. Am. Chem. Soc. 2003, 125, 3168-3180. [CrossRef] [PubMed] 
16. Levy, R.; Sobolev, V.; Edelman, M. First- and second-shell metal binding residues in human proteins are disproportionately associated with disease-related SNPs. Hum. Mutat. 2011, 32, 1309-1318. [CrossRef] [PubMed]

17. Dokmanić, I.; Sikić, M.; Tomić, S. Metals in proteins: Correlation between the metal-ion type, coordination number and the amino-acid residues involved in the coordination. Acta Crystallogr. D Biol. Crystallogr. 2008, 64, 257-263. [CrossRef] [PubMed]

18. Rulísek, L.; Vondrásek, J. Coordination geometries of selected transition metal ions $\left(\mathrm{Co}^{2+}, \mathrm{Ni}^{2+}, \mathrm{Cu}^{2+}, \mathrm{Zn}^{2+}\right.$, $\mathrm{Cd}^{2+}$, and $\mathrm{Hg}^{2+}$ ) in metalloproteins. J. Inorg. Biochem. 1998, 71, 115-127. [CrossRef]

19. Harding, M.M. The architecture of metal coordination groups in proteins. Acta Crystallogr. D Biol. Crystallogr. 2004, 60, 849-859. [CrossRef] [PubMed]

20. Harding, M.M. Geometry of metal-ligand interactions in proteins. Acta Crystallogr. D Biol. Crystallogr. 2001, 57, 401-411. [CrossRef]

21. Harding, M.M. The geometry of metal-ligand interactions relevant to proteins. Acta Crystallogr. D Biol. Crystallogr. 1999, 55, 1432-1443. [CrossRef]

22. Harding, M.M. The geometry of metal-ligand interactions relevant to proteins. II. Angles at the metal atom, additional weak metal-donor interactions. Acta Crystallogr. D Biol. Crystallogr. 2000, 56, 857-867. [CrossRef]

23. Zheng, H.; Chruszcz, M.; Lasota, P.; Lebioda, L.; Minor, W. Data mining of metal ion environments present in protein structures. J. Inorg. Biochem. 2008, 102, 1765-1776. [CrossRef] [PubMed]

24. Andreini, C.; Bertini, I.; Rosato, A. Metalloproteomes: A bioinformatic approach. Acc. Chem. Res. 2009, 42, 1471-1479. [CrossRef] [PubMed]

25. Good, N.M.; Vu, H.N.; Suriano, C.J.; Subuyuj, G.A.; Skovran, E.; Martinez-Gomez, N.C. Pyrroloquinoline quinone ethanol dehydrogenase in Methylobacterium extorquens AM1 extends lanthanide-dependent metabolism to multicarbon substrates. J. Bacteriol. 2016, 198, 3109-3118. [CrossRef] [PubMed]

26. Panichev, A.M. Rare Earth Elements: Review of medical and biological properties and their abundance in the rock materials and mineralized spring waters in the context of animal and human geophagia reason evaluation. Achiev. Life Sci. 2015, 9, 95-103. [CrossRef]

27. Brittain, H.G.; Richardson, F.S.; Martin, R.B. Terbium(III) emission as a probe of calcium(II) binding sites in proteins. J. Am. Chem. Soc. 1976, 98, 8255-8260. [CrossRef]

28. Blomberg, M.R.A.; Borowski, T.; Himo, F.; Liao, R.-Z.; Siegbahn, P.E.M. Quantum chemical studies of mechanisms for metalloenzymes. Chem. Rev. 2014, 114, 3601-3658. [CrossRef]

29. Siegbahn, P.E.M. Mechanisms of metalloenzymes studied by quantum chemical methods. Q. Rev. Biophys. 2003, 36, 91-145. [CrossRef]

30. Chen, S.-L.; Fang, W.-H.; Himo, F. Technical aspects of quantum chemical modeling of enzymatic reactions: The case of phosphotriesterase. Theor. Chem. Account. 2008, 120, 515-522. [CrossRef]

31. Siegbahn, P.E.M. Modeling Aspects of Mechanisms for Reactions Catalyzed by Metalloenzymes. J. Comput. Chem. 2001, 22, 1634-1645. [CrossRef]

32. Sheng, X.; Kazemi, M.; Planas, F.; Himo, F. Modeling enzymatic enantioselectivity using quantum chemical methodology. ACS Catal. 2020, 10, 6430-6449. [CrossRef]

33. Himo, F. Recent trends in quantum chemical modeling of enzymatic reactions. J. Am. Chem. Soc. 2017, 139, 6780-6786. [CrossRef] [PubMed]

34. Piazzetta, P.; Marino, T.; Russo, N.; Salahub, D. The role of metal substitution in the promiscuity of natural and artificial carbonic anhydrases. Coord. Chem. Rev. 2017, 345, 73-85. [CrossRef]

35. Prejanò, M.; Marino, T.; Russo, N. QM cluster or QM/MM in computational enzymology: The test case of LigW-decarboxylase. Front. Chem. 2018, 6, 249. [CrossRef] [PubMed]

36. Ramos, M.J.; Fernandes, P.A. Computational Enzymatic Catalysis. Acc. Chem. Res. 2008, 41, 689-698. [CrossRef] [PubMed]

37. Sousa, S.F.; Fernandes, P.A.; Ramos, M.J. Computational enzymatic catalysis-Clarifying enzymatic mechanisms with the help of computers. Phys. Chem. Chem. Phys. 2012, 14, 12431-12441. [CrossRef] [PubMed]

38. Frisch, M.J.; Trucks, G.W.; Schlegel, H.B.; Scuseria, G.E.; Robb, M.A.; Cheeseman, J.R.; Scalmani, G.; Barone, V.; Petersson, G.A.; Nakatsuji, H. Gaussian 09, Revision D.01; Gaussian Inc.: Wallingford, CT, USA, 2009. 
39. Zhao, Y.; Truhlar, D.G. A new local density functional for main-group thermochemistry, transition metal bonding, thermochemical kinetics, and noncovalent interactions. J. Chem. Phys. A 2006, 125, 194101. [CrossRef] [PubMed]

40. Lee, C.; Yang, W.; Parr, R.G. Development of the Colle-Salvetti correlation-energy formula into a functional of the electron density. Phys. Rev. B 1988, 37, 785-789. [CrossRef]

41. Becke, A.D. A new mixing of Hartree-Fock and local density-functional theories. J. Chem. Phys. 1993, 98, 1372-1377. [CrossRef]

42. Grimme, S.; Antony, J.; Ehrlich, S.; Krieg, H. A consistent and accurate ab initio parameterization of density functional dispersion correction (DFT-D) for the 94 elements H-Pu. J. Chem. Phys. 2010, 132, 154104. [CrossRef]

43. Zhao, Y.; Lynch, B.J.; Truhlar, D.G. Development and assessment of a new hybrid density functional model for thermochemical kinetics. J. Phys. Chem. A 2004, 108, 2715-2719. [CrossRef]

44. Goerigk, L.; Grimme, S. A thorough benchmark of density functional methods for general main group thermochemistry, kinetics, and noncovalent interactions. Phys. Chem. Chem. Phys. 2011, 13, 6670-6688. [CrossRef] [PubMed]

45. Sousa, S.F.; Fernandes, P.A.; Ramos, M.J. General performance of density functionals. J. Phys. Chem. A 2007, 111, 10439-10452. [CrossRef] [PubMed]

46. Shil, S.; Bhattacharya, D.; Sarkar, S.; Misra, A. Performance of the widely used minnesota density functionals for the prediction of heat of formations, ionization potentials of some benchmarked first row transition metal complexes. J. Phys. Chem. A 2013, 117, 4945-4955. [CrossRef] [PubMed]

47. Mata, R.A.; Suhm, M.A. Benchmarking quantum chemical methods: Are we heading in the right direction? Angew. Chem. In. Ed. 2017, 56, 11011-11018. [CrossRef] [PubMed]

48. Verma, P.; Truhlar, D.G. Status and challenges of density functional theory. Trends Chem. 2020, 2, 302-318. [CrossRef]

49. Andrae, D.; Haußermann, H.; Dolg, M.; Stoll, H.; Preuß, H. Energy-adjustedab initio pseudopotentials for the second and third row transition elements. Theor. Chim. Acta 1990, 77, 123-141. [CrossRef]

50. Glendening, E.D.; Reed, A.E.; Carpenter, J.E.; Weinhold, F. Natural Bond Orbitals, version 3.1.; University of Wisconsin: Madison, WI, USA, 2001.

51. Scalmani, G.; Frisch, M.J. Continuous surface charge polarizable continuum models of solvation. I. General formalism. J. Chem. Phys. 2010, 132, 114110. [CrossRef]

52. Barone, V.; Cossi, M. Quantum calculation of molecular energies and energy gradients in solution by a conductor solvent model. J. Phys. Chem. A 1998, 102, 1995-2001. [CrossRef]

53. Marenich, A.V.; Cramer, C.J.; Truhlar, D.G. Universal solvation model based on solute electron density and a continuum model of the solvent defined by the bulk dielectric constant and atomic surface tensions. J. Phys. Chem. B 2009, 113, 6378-6396. [CrossRef]

54. Amata, O.; Marino, T.; Russo, N. Catalytic activity of a æ-class zinc and cadmium containing carbonic anhydrase. Compared work mechanisms. Phys. Chem. Chem. Phys. 2011, 13, 3468-3477. [CrossRef]

55. Chen, W.; Fang, W.H.; Himo, F. Reaction mechanism of the binuclear zinc enzyme glyoxalase II-A theoretical study. J. Inorg. Biochem. 2009, 103, 274-281. [CrossRef] [PubMed]

56. Liao, R.Z.; Himo, F.; Yu, J.G.; Liu, R.Z. Dipeptide hydrolysis by the dinuclear zinc enzyme human renal dipeptidase: Mechanistic insights from DFT calculations. J. Inorg. Biochem. 2010, 104, 37-46. [CrossRef] [PubMed]

57. Sousa, S.F.; Fernandes, P.A.; Ramos, M.J. The search for the mechanism of the reaction catalyzed by farnesyltransferase. Chem. Eur. J. 2009, 15, 4243-4247. [CrossRef] [PubMed]

58. Alberto, M.E.; Marino, T.; Ramos, M.J.; Russo, N. Atomistic details of the catalytic mechanism of Fe(III)-Zn(II) purple acid phosphatase. J. Chem. Theory Comput. 2010, 6, 2424-2433. [CrossRef]

59. Warshel, A. Computer Modeling of Chemical Reactions in Enzymes and Solutions; Wiley: New York, NY, USA, 1991.

60. Piazzetta, P.; Marino, T.; Russo, N. Insight into the promiscuous activity of human carbonic anhydrase against the cyanic acid substrate from a combined QM and QM/MM investigation. Phys. Chem. Chem. Phys. 2014, 16, 16671-16676. [CrossRef]

61. Ribeiro, A.J.M.; Alberto, M.E.; Ramos, M.J.; Fernandes, P.A.; Russo, N. The catalytic mechanism of protein phosphatase 5 established by DFT calculations. Chem. Eur. J. 2013, 114, 3601-3658. [CrossRef] 
62. Liao, R.Z.; Yu, G.; Himo, F. Mechanism of tungsten-dependent acetylene hydratase from quantum chemical calculations. Proc. Natl. Acad. Sci. USA 2010, 107, 22523-22527. [CrossRef]

63. Quesne, M.G.; Borowski, T.; de Visser, S.P. Quantum mechanics/molecular mechanics modeling of enzymatic processes: Caveats and breakthroughs. Chem. Eur. J. 2016, 22, 2562-2581. [CrossRef]

64. Van der Kamp, M.W.; Mulholland, A.J. Combined quantum mechanics/molecular mechanics (QM/MM) methods in computational enzymology. Biochemistry 2013, 52, 2708-2728. [CrossRef]

65. Sousa, S.F.; Ribeiro, A.J.M.; Neves, R.P.P.; Brás, N.F.; Cerqueira, N.M.F.S.A.; Fernandes, P.A.; Ramos, M.J. Application of quantum mechanics/molecular mechanics methods in the study of enzymatic reaction mechanisms. Comput. Mol. Sci. 2017, 7, e1281. [CrossRef]

66. Swiderek, K.; Tunon, I.; Moliner, V. Predicting enzymatic reactivity: From theory to design. Comput. Mol. Sci. 2014, 4, 407-421. [CrossRef]

67. Kamerlin, S.C.L.; Warshel, A. The empirical valence bond model: Theory and applications. Comput. Mol. Sci. 2011, 1, 30-45. [CrossRef]

68. Brunk, E.; Rothlisberger, U. Mixed quantum mechanical/molecular mechanical molecular dynamics simulations of biological systems in ground and electronically excited states. Chem. Rev. 2015, 115, 6217-6263. [CrossRef]

69. Anthony, C. Methanol Dehydrogenase, a PQQ-Containing Quinoprotein Dehydrogenase; Holzenburg, A., Scrutton, N.S., Eds.; Springer: New York, NY, USA, 2000; pp. 73-117.

70. Kalyuzhnaya, M.G.; Hristova, K.R.; Lidstrom, M.E.; Chistoserdova, L. Characterization of a novel methanol dehydrogenase in representatives of burkholderiales: Implications for environmental detection of methylotrophy and evidence for convergent evolution. J. Bacteriol. 2008, 190, 3817-3823. [CrossRef] [PubMed]

71. Duine, J.A.; Frank, J.; Westerling, J. Purification and properties of methanol dehydrogenase from Hyphomicrobium X. Biochim. Biophys. Acta 1978, 524, 277-287. [CrossRef]

72. Ghosh, R.; Quayle, J.R. Purification and properties of the methanol dehydrogenase from Methylophilis methylotrophus. Biochem. J. 1981, 199, 245-250. [CrossRef]

73. Parker, M.W.; Cornish, A.; Gossain, V.; Best, D.J. Purification, crystallization and preliminary X-ray diffraction characterization of methanol dehydrogenase from Methylosinus trichosporium OB3b. Eur. J. Biochem. 1987, 164, 223-227. [CrossRef]

74. Williams, P.A.; Coates, L.; Mohammed, F.; Gill, R.; Erskine, P.T.; Coker, A.; Woods, S.P.; Anthony, C.; Cooper, J.B. The atomic resolution structure of methanol dehydrogenase from Methylobacterium extorquens. Acta Crystallogr. D 2005, 61, 75-79. [CrossRef]

75. Xia, Z.; Dai, W.; Zhang, Y.; White, S.A.; Boyd, G.D.; Mathews, F.S. Determination of the gene sequence and the three-dimensional structure at 2.4 angstroms resolution of methanol dehydrogenase from Methylophilus W3A1. J. Mol. Biol. 1996, 259, 480-501. [CrossRef]

76. Chistoserdova, L. Metabolism of Formaldehyde in M. extorquens AM1. Molecular Genetic Analysis and Mutant Characterization; Lidstrom, M.E., Tabita, F.R., Eds.; Kluwer Academic Publishers: Dordrecht, The Netherlands, 1996; pp. 16-24.

77. Harms, N.; Ras, J.; Koning, S.; Reijinders, W.N.M.; Stouthamer, A.H.; van Spanning, R.J.M. Genetics of C1 Metabolism Regulation in Paracoccus Denitrificans; Lidstrom, M.E., Tabita, F.R., Eds.; Kluwer Academic Publishers: Dordrecht, The Netherlands, 1996; pp. 126-132.

78. Hibi, Y.; Asai, K.; Arafuka, H.; Hamajima, M.; Iwama, T.; Kawai, K. Molecular structure of La3+-induced methanol dehydrogenase-like protein in Methylobacterium radiotolerans. J. Biosci. Bioeng. 2011, 111, 547-549. [CrossRef]

79. Anthony, C. The quinoprotein dehydrogenases for methanol and glucose. Arch. Biochem. Biophys. 2004, 428, 2-9. [CrossRef] [PubMed]

80. Goodwin, P.M.; Anthony, C. The biochemistry, physiology and genetics of PQQ and PQQ-containing enzymes. Adv. Microb. Physiol. 1998, 40,1-80. [PubMed]

81. Pol, A.; Barends, T.R.M.; Dietl, A.; Khadem, A.F.; Eygensteyn, J.; Jetten, M.S.M.; Op den Camp, H.J.M. Rare earth metals are essential for methanotrophic life in volcanic mudpots. Enviromental Microbiol. 2014, 16, 255-264. [CrossRef] [PubMed]

82. Djinovic-Carugo, K.; Carugo, O. Structural biology of the lanthanides-mining rare earths in the Protein Data Bank. J. Inorg. Biochem. 2015, 143, 69-76. [CrossRef] [PubMed] 
83. Martin, R.B.; Richardson, F.S. Lanthanides as probes for calcium in biological systems. Q. Rev. Biophys. 1979, 12, 181-209. [CrossRef]

84. Dos Remedios, C.G. Lanthanide ion probes of calcium-binding sites on cellular membranes. Cell Calcium 1981, 2, 29-51. [CrossRef]

85. Mikkelson, R.B. Lanthanides as Calcium Probes; Chapman, D., Wallach, D.F., Eds.; Academic Press: New York, NY, USA, 1976; pp. 153-190.

86. Anthony, C. Methanol dehydrogenase, a PQQ-containing quinoprotein dehydrogenase. Subcell. Biochem. 2000, 35, 73-117.

87. Idupulapati, N.B.; Minardi, D.S. Coordination and binding of ions in $\mathrm{Ca}^{2+}$ - and $\mathrm{Ba}^{2+}$-containing methanol dehydrogenase and interactions with methanol. Theochem 2009, 901, 72-80. [CrossRef]

88. Good, N.M.; Fellner, M.; Demirer, K.; Hu, J.; Hausinger, R.P.; Martinez-Gomez, N.C. Lanthanide-dependent alcohol dehydrogenases require an essential aspartate residue for metal coordination and enzymatic function. J. Biol. Chem. 2020, 295, 8272-8284. [CrossRef]

89. Reddy, S.Y.; Bruice, T.C. Determination of enzyme mechanisms by molecular dynamics: Studies on quinoproteins, methanol dehydrogenase, and soluble glucose dehydrogenase. Protein Sci. 2004, 13, 1965-1978. [CrossRef]

90. Jahn, B.; Pol, A.; Lumpe, H.; Barends, T.R.M.; Dietl, A.; Hogendoorn, C.; Op den Camp, H.J.M.; Daumann, L.J. Similar but not the same: First kinetic and structural analyses of a methanol dehydrogenase containing a europium ion in the active site. ChemBioChem 2018, 19, 1147-1153. [CrossRef] [PubMed]

91. Idupulapati, N.B.; Mainardi, D. Quantum chemical modeling of methanol oxidation mechanisms by methanol dehydrogenase enzyme: Effect of substitution of calcium by barium in the active site. J. Phys. Chem. A 2010, 114, 1887-1896. [CrossRef] [PubMed]

92. Fitriyanto, N.A.; Fushimi, M.; Matsunaga, M.; Pertiwiningrum, A.; Iwama, T.; Kawai, K. Molecular structure and gene analysis of $\mathrm{Ce}^{3+}$-Induced methanol dehydrogenase of Bradyrhizobium sp. MAFF211645. J. Biosci. Bioeng. 2011, 111, 613-617. [CrossRef] [PubMed]

93. Nakagawa, T.; Mitsui, R.; Tani, A.; Sasa, K.; Tashiro, S.; Iwama, T.; Hayakawa, T.; Kawai, K. A Catalytic role of XoxF1 as $\mathrm{La}^{3+}$-Dependent methanol Dehydrogenase in Methylobacterium extorquens Strain AM1. PLoS ONE 2012, 7, e50480. [CrossRef] [PubMed]

94. Daumann, L.J. Essential and Ubiquitous: The Emergence of Lanthanide Metallobiochemistry. Angew. Chem. Int. Ed. 2019, 58, 12795-12802. [CrossRef]

95. Lumpe, H.; Pol, A.; Op den Camp, H.J.M.; Daumann, L.J. Impact of the lanthanide contraction on the activity of a lanthanide-dependent methanol dehydrogenase-A kinetic and DFT study. Dalton Trans. 2018, 47, 10463-10472. [CrossRef]

96. Huang, J.; Yu, Z.; Groom, J.; Cheng, J.F.; Tarver, A.; Yoshikuni, Y.; Chistoserdova, L. Rare earth element alcohol dehydrogenases widely occur among globally distributed, numerically abundant and environmentally important microbes. ISME J. 2019, 13, 2005-2017. [CrossRef]

97. Lumpe, H.; Daumann, L.J. Studies of redox cofactor pyrroloquinoline quinone and its interaction with Lanthanides(III) and Calcium(II). Inorg. Chem. 2019, 58, 8432-8441. [CrossRef]

98. Bogart, J.A.; Lewis, A.J.; Schelter, E.J. DFT Study of the Active Site of the XoxF-Type Natural, Cerium-dependent methanol dehydrogenase enzyme. Chem. Eur. J. 2015, 21, 1743-1748. [CrossRef]

99. McSkimming, A.; Cheisson, T.; Carroll, P.J.; Schelter, E.J. Functional synthetic model for the lanthanide-dependent quinoid alcohol dehydrogenase active site. J. Am. Chem. Soc. 2018, 140, 1223-1226. [CrossRef]

100. Marino, T.; Prejanò, M.; Russo, N. How Metal Coordination in the Ca-, Ce-, and Eu-Containing Methanol Dehydrogenase Enzymes Can Influence the Catalysis: A Theoretical Point of View; Broclawick, E., Borowski, T., Radoń, M., Eds.; Springer: Cham, Switzerland, 2019; pp. 487-501.

101. Cotton, S.A.; Raithby, P.R. Systematics and surprises in lanthanide coordination chemistry. Coord. Chem. Rev. 2017, 340, 220-231. [CrossRef]

102. Seitz, M.; Oliver, A.G.; Raymond, K.N. The lanthanide contraction revisited. J. Am. Chem. Soc. 2007, 129, 11153-11160. [CrossRef] [PubMed]

103. Pyykkö, P. Relativistic effects in structural chemistry. Chem. Rev. 1988, 88, 563-594. [CrossRef]

104. Hothi, P.; Sutcliffe, M.J.; Scrutton, N.S. Kinetic isotope effects and ligand binding in PQQ-dependent methanol dehydrogenase. Biochem. J. 2005, 388, 123-133. [CrossRef] 
105. Prejanò, M.; Marino, T.; Russo, N. How can methanol dehydrogenase from Methylacidiphilum fumariolicum work with the alien CeIII ion in the active center? A theoretical study. Chem. Eur. J. 2017, 23, 8652-8657. [CrossRef]

106. Prejanò, M.; Russo, N.; Marino, T. How the lanthanide ions affect the addition-elimination step of methanol dehydrogenases. Chem. Eur. J. 2020. [CrossRef]

107. Leopoldini, M.; Russo, N.; Toscano, M. The preferred reaction path for the oxidation of methanol by PQQ-containing methanol dehydrogenase: Addition-elimination versus hydride transfer mechanism. Chem. Eur. J. 2007, 13, 2109-2117. [CrossRef]

108. Hazardous Substances Databank; U.S. National Library of Medicine: Bethesda, MD, USA, 1995.

109. Woutersen, R.A. Psychosocial factors at work and subsequent depressive symptoms in the Gazel cohort. Scand. J. Work. Environ. Health 1998, 24, 197-205.

110. Wyatt, J.M.; Knowles, C.J. Microbial degradation of acrylonitrile waste effluents: The degradation of effluents and condensates from the manufacture of acrylonitrile. Int. Biodeterior. Biodegrad. 1995, 35, 227-248. [CrossRef]

111. Martinez, S.; Wu, R.; Sanishvili, R.; Liu, D.; Holz, R. The Active site sulfenic acid ligand in nitrile Hydratases can function as a nucleophile. J. Am. Chem. Soc. 2014, 136, 1186-1189. [CrossRef]

112. Kobayashi, M.; Shimizu, S. Metalloenzyme nhase: Structure, regulation and application to biotechnology. Nat. Biotechnol. 1998, 16, 733-736. [CrossRef]

113. Schmid, A.; Dordick, J.S.; Hauer, B.; Kiener, A.N.; Wubbolts, M.; Witholt, B. Industrial biocatalysis today and tomorrow. Nature 2001, 409, 258-268. [CrossRef]

114. Cheng, Z.; Xia, Y.; Zhou, Z. Recent advances and promises in nitrile hydratase: From mechanism to industrial applications. Front. Bioeng. Biotechnol. 2020, 8, 352. [CrossRef] [PubMed]

115. Baxter, J.; Cummings, S. The current and future applications of microorganism in the bioremediation of cyanide contamination. Antonie Leeuwenhoek 2006, 90, 1-17. [CrossRef] [PubMed]

116. Ashima, Y.; Suto, M. Development of an enzymatic process for manufacturing acrylamide and recent progress. Bioprocess. Technol. 1993, 16, 91-107.

117. Kobayashi, M.; Nagasawa, T.; Yamada, H. Enzymatic synthesis of acrylamide: A success story not yet over. Trends Biotechnol. 1992, 10, 402-408. [CrossRef]

118. Yamada, H.; Kobayashi, M. Nitrile hydratase and its application to industrial production of acrylamide. Biosci. Biotechnol. Biochem. 1996, 60, 1391-1400. [CrossRef] [PubMed]

119. Payne, M.S.; Wu, S.; Fallon, R.D.; Tudor, G.; Stieglitz, B.; Turner, I.M., Jr.; Nelson, M.J. A stereoselective cobalt-containing nitrile hydratase. Biochemistry 1997, 36, 5447-5454. [CrossRef]

120. Mascharak, P.K. Structural and functional models of nitrile hydratase. Coord. Chem. Rev. 2002, 225, $201-214$. [CrossRef]

121. Hopmann, K.H.; Himo, F. Theoretical Investigation of the Second-Shell Mechanism of Nitrile Hydratase. Eur. J. Inorg. Chem. 2008, 20, 1406-1412. [CrossRef]

122. Light, K.M.; Yamanaka, Y.; Odaka, M.; Solomon, E.I. Spectroscopic and computational studies of nitrile hydratase: Insights into geometric and electronic structure and the mechanism of amide synthesis. Chem. Sci. 2015, 6, 6280-6294. [CrossRef] [PubMed]

123. Kovacs, J.A. Synthetic analogues of cysteinate-ligated non-heme iron and non-corrinoid cobalt enzymes. Chem. Rev. 2004, 104, 825-848. [CrossRef] [PubMed]

124. Stein, N.; Gumataotao, N.; Hajnas, N.; Wu, R.; Lankathilaka, K.P.W.; Bornscheuer, U.T.; Liu, D.; Fiedler, A.T.; Holz, R.C.; Bennett, B. Multiple states of nitrile hydratase from rhodococcus equi TG328-2: Structural and mechanistic insights from electron paramagnetic resonance and density functional theory studies. Biochemistry 2017, 56, 3068-3077. [CrossRef] [PubMed]

125. Banerjee, A.; Sharma, R.; Banerjee, U. The nitrile-degrading enzymes: Current status and future prospects. Appl. Microbiol. Biotechnol. 2002, 60, 33-44. [CrossRef]

126. Mylerova, V.; Martinkova, L. Synthetic applications of nitrileconverting enzymes. Curr. Org. Chem. 2003, 7, 1279-1295.

127. Miyanaga, A.; Fushinobu, S.; Ito, K.; Wakagi, T. Crystal structure of cobalt-containing nitrile hydratase. Biochem. Biophys. Res. Commun. 2001, 288, 1169-1174. [CrossRef] 
128. Hashimoto, K.; Suzuki, H.; Taniguchi, K.; Noguchi, T.; Yohda, M.; Odaka, M. Catalytic mechanism of nitrile hydratase proposed by time-resolved X-ray crystallography using a novel substrate, tertButylisonitrile. J. Biol. Chem. 2008, 283, 36617-36623. [CrossRef]

129. Dey, A.; Chow, M.; Taniguchi, K.; Lugo-Mas, P.; Davin, S.; Maeda, M.; Kovacs, J.A.; Odaka, M.; Hodgson, K.O.; Hedman, B.; et al. Sulfur K-Edge XAS and DFT calculations on nitrile hydratase: Geometric and electronic structure of the non-heme iron active site. J. Am. Chem. Soc. 2006, 128, 533-541. [CrossRef]

130. Yamanaka, Y.; Kato, Y.; Hashimoto, K.; Iida, K.; Nagasawa, K.; Nakayama, H.; Dohmae, N.; Noguchi, K.; Noguchi, T.; Yohda, M.; et al. Time-resolved crystallography of the reaction intermediate of nitrile hydratase: Revealing a role for the cysteine sulfenic acid ligand as a catalytic nucleophile. Angew. Chem. Int. Ed. 2015, 54, 10763-10767. [CrossRef]

131. Hopmann, K.H.; Guo, J.-D.; Himo, F. Theoretical investigation of the first-shell mechanism of nitrile hydratase. Inorg. Chem. 2007, 46, 4850-4856. [CrossRef]

132. Prejanò, M.; Marino, T.; Rizzuto, C.; Madrid Madrid, J.C.; Russo, N.; Toscano, M. Reaction mechanism of low-spin Iron(III)- and Cobalt(III)-containing nitrile hydratases: A quantum mechanics investigation. Inorg. Chem. 2017, 58, 13390-13400. [CrossRef] [PubMed]

133. Hopmann, K.H.; Himo, F. On the role of tyrosine as catalytic base in nitrile hydratase. Eur. J. Inorg. Chem. 2008, 22, 3452-3459. [CrossRef]

134. Hopmann, K.H. Full reaction mechanism of nitrile hydratase: A cyclic intermediate and an unexpected disulfide switch. Inorg. Chem. 2014, 53, 2760-2762. [CrossRef] [PubMed]

135. Kayanuma, M.; Hanaoka, K.; Shoji, M.; Shigeta, Y. A QM/MM study of the initial steps of catalytic mechanism of nitrile hydratase. Chem. Phys. Lett. 2015, 623, 8-13. [CrossRef]

136. Kayanuma, M.; Shoji, M.; Yohda, M.; Odaka, M.; Shigeta, Y. Catalytic mechanism of nitrile hydratase subsequent to cyclic intermediate formation: A QM/MM study. J. Phys. Chem. B 2016, 120, 3259-3266. [CrossRef]

137. Takarada, H.; Kawano, Y.; Hashimoto, K.; Nakayama, H.; Ueda, S.; Yohda, M.; Kamiya, N.; Dohmae, N.; Maeda, M.; Odaka, M. Mutational study on $\alpha \mathrm{Gln} 90$ of Fe-type nitrile hydratase from Rhodococcus sp. N771. Biosci. Biotechnol. Biochem. 2006, 70, 881-889. [CrossRef]

138. Di Costanzo, L.; Sabio, G.; Mora, A.; Rodriguez, P.C.; Ochoa, A.C.; Centeno, F.; Christianson, D.W. Crystal structure of human arginase I at 1.29-A resolution and exploration of inhibition in the immune response. Proc. Natl. Acad. Sci. USA 2005, 102, 13058-13063. [CrossRef]

139. Di Costanzo, L.; Moulin, M.; Haertlein, M.; Meilleur, F.; Christianson, D.W. Expression, purification, assay, and crystal structure of perdeuterated human arginase I. Arch. Biochem. Biophys. 2007, 465, 82-89. [CrossRef]

140. Hellerman, L.A.; Perkins, M.E. Activation of enzymes III. The role of metal Ions in the activation od arginase. The hydrolysis of arginine induced by certain metal ions with urease. J. Biol. Chem. 1935, 112, 175-194.

141. .Hellerman, L.A. Reversible inactivations of certain hydrolytic enzymes. Physiol. Rev. 1937, 17, 454-484. [CrossRef]

142. Stone, E.M.; Glazer, E.S.; Chantranupong, L.; Cherukuri, P.; Breece, R.M.; Thierney, D.L.; Curley, S.A.; Iverson, B.L.; Georgiou, G. Replacing $\mathrm{Mn}^{2+}$ with $\mathrm{Co}^{2+}$ in human arginase i enhances cytotoxicity toward 1-arginine auxotrophic cancer cell lines. ACS Chem. Biol. 2010, 5, 333-342. [CrossRef] [PubMed]

143. D'Antonio, E.L.; Chirstianson, D.W. Crystal structures of complexes with cobalt-reconstituted human arginase I. Biochemistry 2011, 50, 8018-8027. [CrossRef] [PubMed]

144. Penninckx, M.; Simon, J.P.; Wiame, J.M. Interaction between arginase and L-ornithine carbamoyltransferase in Saccharomyces cerevisiae. Purification of S. cerevisiae enzymes and evidence that these enzymes as well as rat-liver arginase are trimers. Eur. J. Biochem. 1974, 49, 429-442. [CrossRef]

145. Kanyo, Z.F.; Scolnick, L.R.; Ash, D.E.; Christianson, D.W. Structure of a unique binuclear manganese cluster in arginase. Nature 1996, 383, 554-557. [CrossRef]

146. Cox, J.D.; Kim, N.N.; Traish, A.M.; Christianson, D.W. Arginase-boronic acid complex highlights a physiological role in erectile function. Nat. Struct. Biol. 1999, 6, 1043-1048.

147. Khangulov, S.V.; Sossong, T.M., Jr.; Ash, D.E.; Dismukes, G.C. 1-Arginine binding to liver arginase Requires proton transfer to gateway residue His141 and coordination of the guanidinium group to the Dimanganese(II,II) center. Biochemistry 1998, 37, 8539-8550. [CrossRef] [PubMed] 
148. Bewley, M.C.; Jeffrey, P.D.; Patchett, M.L.; Kanyo, Z.F.; Aker, E.N. Crystal structures of Bacillus caldovelox arginase in complex with substrate and inhibitors reveal new insights into activation, inhibition and catalysis in the arginase superfamily. Structure 1999, 7, 435-448. [CrossRef]

149. Cama, E.; Emig, F.A.; Ash, D.E.; Christianson, D.W. Structural and functional importance of first-shell metal ligands in the binuclear manganese cluster of arginase I. Biochemistry 2003, 42, 7748-7758. [CrossRef] [PubMed]

150. Leopoldini, M.; Russo, N.; Toscano, M. Determination of the catalytic pathway of a manganese arginase enzyme through density functional investigation. Chem. Eur. J. 2009, 15, 8026-8036. [CrossRef]

151. Marino, T.; Russo, N.; Toscano, M. What occurs by replacing $\mathrm{Mn}^{2+}$ with $\mathrm{Co}^{2+}$ in human arginase I: First-principles computational analysis. Inorg. Chem. 2013, 52, 655-659. [CrossRef]

152. Srivastava, A.; Dwivedi, N.; Samanta, U.; Sau, A.K. Insight into the role of a unique SSEHA motif in the activity and stability of Helicobacter pylori arginase. IUBMB Life 2011, 63, 1027-1036. [CrossRef] [PubMed]

153. Velázquez-Libera, J.L.; Caballero, J.; Tuñón, I.; Hernández-Rodríguez, E.W.; Ruiz-Pernía, J. On the nature of the enzyme-substrate complex and the reaction mechanism in human arginase I. A combined molecular dynamics and QM/MM study. ACS Catal. 2020, 10, 8321-8333. [CrossRef]

(C) 2020 by the authors. Licensee MDPI, Basel, Switzerland. This article is an open access article distributed under the terms and conditions of the Creative Commons Attribution (CC BY) license (http://creativecommons.org/licenses/by/4.0/). 